\title{
Technical Note: Chemistry-climate model SOCOL: version 2.0 with improved transport and chemistry/microphysics schemes
}

\author{
M. Schraner ${ }^{1,2}$, E. Rozanov ${ }^{1,2}$, C. Schnadt Poberaj ${ }^{1}$, P. Kenzelmann ${ }^{1}$, A. M. Fischer ${ }^{1}$, V. Zubov ${ }^{3}$, B. P. Luo ${ }^{1}$, \\ C. R. Hoyle ${ }^{4}$, T. Egorova ${ }^{2}$, S. Fueglistaler ${ }^{5}$, S. Brönnimann ${ }^{1}$, W. Schmutz ${ }^{2}$, and T. Peter ${ }^{1}$ \\ ${ }^{1}$ Institute for Atmospheric and Climate Science, ETH Zürich, Switzerland \\ ${ }^{2}$ Physical-Meteorological Observatory/World Radiation Center, Davos, Switzerland \\ ${ }^{3}$ Main Geographical Observatory, St.-Petersburg, Russia \\ ${ }^{4}$ Department of Geosciences, University of Oslo, Norway \\ ${ }^{5}$ DAMTP, University of Cambridge, UK
}

Received: 8 April 2008 - Published in Atmos. Chem. Phys. Discuss.: 9 June 2008

Revised: 1 September 2008 - Accepted: 4 September 2008 - Published: 15 October 2008

\begin{abstract}
We describe version 2.0 of the chemistry-climate model (CCM) SOCOL. The new version includes fundamental changes of the transport scheme such as transporting all chemical species of the model individually and applying a family-based correction scheme for mass conservation for species of the nitrogen, chlorine and bromine groups, a revised transport scheme for ozone, furthermore more detailed halogen reaction and deposition schemes, and a new cirrus parameterisation in the tropical tropopause region. By means of these changes the model manages to overcome or considerably reduce deficiencies recently identified in SOCOL version 1.1 within the CCM Validation activity of SPARC (CCMVal). In particular, as a consequence of these changes, regional mass loss or accumulation artificially caused by the semi-Lagrangian transport scheme can be significantly reduced, leading to much more realistic distributions of the modelled chemical species, most notably of the halogens and ozone.
\end{abstract}

\section{Introduction}

Projection of the global climate and the ozone layer is one of the central questions in the contemporary geosciences (IPCC, 2007; WMO, 2006). The behaviour of the climate system depends on the multitude of external forcings, on physical, chemical and dynamical processes in the atmo-

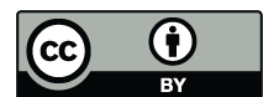

Correspondence to: M. Schraner (martin.schraner@env.ethz.ch) sphere, and on their nonlinear interactions. Therefore, it can be properly assessed only with sophisticated chemistryclimate models (CCMs), which are able to treat the relevant processes (Eyring et al., 2006). On the other hand, the nonlinearity of the system and uncertainty in the forcing scenarios require multiple long-term model ensemble runs, which are feasible only with models being computationally not too expensive. As a result, the limitations of a CCM caused by the lack of complete knowledge of nature, as well as by simplified descriptions of unresolved processes are further aggravated by the necessity to exploit the fastest, but not the most accurate modules for many important processes. Thus, any CCM represents a compromise between our ambition to have a perfect model based on the first principles and the limits of possibility. To judge the success of this compromise, it is necessary to validate the models against observations. In previous years, CCMs have been extensively evaluated (e.g., Austin et al., 2003; Eyring et al., 2006). In these evaluation studies several of the tested models displayed characteristic weaknesses and deficiencies. For example, stratospheric temperature biases may affect temperature-dependent chemical reaction rates and lead to significant model-to-model variations in the simulation of polar stratospheric cloud (PSC) volumes in polar regions (e.g., Austin et al., 2003). Deficiencies in transport schemes may lead to errors in the temporal and spatial evolution of the distributions of ozone and other chemical species that react with ozone (e.g., Eyring et al., 2006). Biases in chlorine and bromine-containing species, which are often related to deficiencies in transport, may strongly affect the catalytic ozone destruction, especially over Antarctica. Problems in simulating stratospheric

Published by Copernicus Publications on behalf of the European Geosciences Union. 
water vapour may affect the radiative balance, the $\mathrm{HO}_{\mathrm{x}}$ cycles and the formation of PSCs in the models (e.g., Eyring et al., 2006).

The CCM SOCOL (modelling tool for studies of SOlar Climate Ozone Links) under investigation in the present paper has been developed at Physical and Meteorological Observatory/World Radiation Center (PMOD/WRC), Davos in collaboration with ETH Zürich and MPI Hamburg (Egorova et al., 2005). The evaluation of different CCMs within the Chemistry-Climate Model Validation Activity for SPARC, CCMVal (Eyring et al., 2006), revealed that SOCOL has serious problems in simulating the stratospheric chlorine content and water vapour. In the upper stratosphere, the mixing ratio of total inorganic $\mathrm{Cl}_{\mathrm{y}}$ simulated by the CCM SOCOL was up to $30 \%$ higher than that of the maximum total chlorine entering the stratosphere. In contrast, in the lower stratosphere of the southern high latitudes total inorganic $\mathrm{Cl}_{\mathrm{y}}$ was shown to be significantly underestimated by SOCOL (1.1 ppbv at $50 \mathrm{hPa}, 80^{\circ} \mathrm{S}$ for October 1992, in contrast to $3.0 \mathrm{ppbv}$ from estimates based on HALOE observations; Eyring et al. (2006), their Fig. 12). Water vapour was overestimated by $30-40 \%$ in the whole stratosphere (see Eyring et al. (2006), their Fig. 6). On the other hand, it was shown that SOCOL satisfactorily represents the distributions of many other trace gases outside the southern polar vortex, as well as atmospheric temperature and dynamics. Owing to SOCOL's excellent computational efficiency and portability allowing its application for long-term ensemble runs on regular personal computers (Egorova et al., 2005), we were able to evaluate possible causes of the model deficiencies and to overcome them in a physically meaningful manner without dramatic and expensive redesign of the entire model. In the present paper, we illustrate a step-by-step evaluation of the problems in SOCOL and the implementation of specific changes in the transport and chemical modules leading to significantly improved model performance. We believe that our efforts will be useful for other modelling groups having similar problems with chemistry and transport representation in their models.

In the following, we will refer to the original version of SOCOL described by Egorova et al. (2005) and Rozanov et al. (2005) as SOCOL vs1.0, the SOCOL version participating in the CCMVal evaluation of Eyring et al. (2006) as SOCOL vs1.1, and the new version presented in this paper as SOCOL vs2.0. This paper is organized as follows. Sect. 2 gives a model description of SOCOL vs1.1. Section 3 describes the boundary conditions and model set up of the simulations described in this paper. In Sect. 4, all modifications leading from SOCOL vs1.1 to SOCOL vs2.0 are described (via sub-versions termed vs1.2 to vs1.5) and the changes in relevant chemical and dynamical fields resulting from the model modifications are discussed. In Sect. 5, results from the new model version SOCOL vs2.0 are compared to observations.

\section{SOCOL vs.1.1: model description}

The CCM SOCOL is a combination of a modified version of the middle atmosphere GCM MA-ECHAM4 (Middle Atmosphere version of the "European Centre/HAmburg Model 4") (Roeckner et al., 1996; Manzini and Bengtsson, 1996) and a modified version of the CTM MEZON (Model for Evaluation of oZONe trends) (Rozanov et al., 1999, 2001; Egorova et al., 2001, 2003; Hoyle, 2005). In the original version SOCOL vs1.0 (Egorova et al., 2005; Rozanov et al., 2005) MA-ECHAM4 and MEZON are interactively coupled by the radiative forcing induced by water vapour and ozone. For SOCOL vs1.1, this coupling was extended to include also methane, nitrous oxide, and chlorofluorocarbons (CFCs).

MA-ECHAM4 is a spectral GCM with T30 horizontal truncation resulting in a geographical grid spacing of about $3.75^{\circ}$. In the vertical direction, the model has 39 levels in a hybrid sigma-pressure coordinate system spanning the model atmosphere from the surface to $0.01 \mathrm{hPa}(\approx 80 \mathrm{~km})$. A semiimplicit time stepping scheme with weak filter is used with a time step of $15 \mathrm{~min}$ for dynamical processes and physical process parameterisations. Full radiative transfer calculations are performed every $2 \mathrm{~h}$, but heating and cooling rates are interpolated every $15 \mathrm{~min}$. The radiation scheme is based on the radiation code of the European Centre of Medium-Range Weather Forecasts, ECMWF (Fouquart and Bonnel, 1980; Morcrette, 1991). In order to obtain realistic heating rates in the upper stratosphere and in the mesosphere, the absorption by $\mathrm{O}_{2}$ and $\mathrm{O}_{3}$ in the Lyman-alpha line, Schumann-Runge bands and part of the ozone Hartley band (below $250 \mathrm{~nm}$, which is not included in MA-ECHAM4) is taken into account in SOCOL vs1.1 (Egorova et al., 2004) using a parameterisation according to Strobel (1978). The parameterisation of momentum flux deposition due to a continuous spectrum of vertically propagating gravity waves follows Hines (1997a, b), gravity wave momentum deposition is described by Doppler spread parameterisation according to Manzini et al. (1997). The Doppler spread parameterisation leads to a significant improvement of the zonal winds in the mesosphere and of the semiannual oscillation of the zonal winds at the stratopause (Manzini et al., 1997).

The chemical-transport part MEZON has the same vertical and horizontal resolution as MA-ECHAM4, and the calculations are performed every $2 \mathrm{~h}$. The model includes 41 chemical species of the oxygen, hydrogen, nitrogen, carbon, chlorine and bromine groups, which are determined by 118 gas-phase reactions, 33 photolysis reactions and 16 heterogeneous reactions in/on aqueous sulphuric acid aerosols, water ice and nitric acid trihydrate (NAT). The parameterisation of heterogeneous chemistry applied in SOCOL vs1.1 is different from SOCOL vs1.0: The new scheme includes $\mathrm{HNO}_{3}$ uptake by aqueous sulphuric acid aerosols (Carslaw et al., 1995) and an improved parameterisation of the liquid-phase reactive uptake coefficients following Hanson and Ravishankara (1994) and Hanson et al. (1996). The PSC scheme 
for water ice uses prescribed particle number densities and assumes the cloud particles to be in thermodynamic equilibrium with their gaseous environment. NAT is formed if the partial pressure of $\mathrm{HNO}_{3}$ exceeds its saturation pressure. A prescribed mean particle radius of $5 \mu \mathrm{m}$ is used for NAT, and the particle number densities are limited by an upper boundary of $5 \times 10^{-4} \mathrm{~cm}^{-3}$ to account for the fact that observed NAT clouds are often strongly supersaturated. The sedimentation of NAT and water ice is described based on the Stokes theory as in Pruppacher and Klett (1997). Water ice and NAT are not explicitly transported, but are evaporated back to water vapour and gaseous $\mathrm{HNO}_{3}$, respectively, after chemical treatment. The reaction coefficients are taken from Sander et al. (2000); photolysis rates are calculated at every chemical time step using a look-up-table approach (Rozanov et al., 1999). The chemical solver is based on the implicit iterative Newton-Raphson scheme (Ozolin, 1992; Stott and Harwood, 1993). The transport of all considered species is calculated using the hybrid numerical advection scheme of Zubov et al. (1999).

\section{Boundary conditions and model set up}

To assess differences between model versions, we performed a transient simulation of the period 1975-2000 for each model version. For all these simulations, the same initial fields and boundary conditions were used as described in this section.

Sea surface temperatures and sea ice distributions (SST/SI) were prescribed according to the Hadley Centre Sea Ice and SST dataset HadISST1 (Rayner et al., 2003) with a monthly resolution. Time-dependent mixing ratios of $\mathrm{CO}_{2}, \mathrm{CH}_{4}, \mathrm{~N}_{2} \mathrm{O}$, and ozone destroying substances (ODS) were based on IPCC (2001) and WMO (2003) and were obtained from the CCMVal website (http://www.pa.op.dlr.de/ CCMVal/Forcings). $\mathrm{CO}$ and $\mathrm{NO}_{\mathrm{x}}$ emissions from industry, traffic, and biomass burning were prescribed by the annually and monthly changing RETRO dataset (Schultz et al., 2008a, $\mathrm{b}^{1}$ ), whereas the $\mathrm{CO}$ and $\mathrm{NO}_{\mathrm{x}}$ emissions from soils and the ocean were based on those used in the model MOZART-2 representing the early 1990s (Horowitz et al., 2003). For $\mathrm{NO}_{\mathrm{x}}$ emissions from aircraft, the time-dependent fields from ECHAM4.L39(DLR)/CHEM (E39/C) were used (Dameris et al., 2005) based on a dataset of Schmitt and Brunner (1997) representative for the year 1992. Changes before 1992 were implemented in accordance with IPCC (1999), whereas an exponential increase was assumed for 19932000. The $\mathrm{NO}_{\mathrm{x}}$ emissions from lightning were based on a satellite-based dataset (Turman and Edgar, 1982) used in the tropospheric CTM IMAGES (Müller and Brasseur, 1995). For stratospheric aerosol densities the "gap-free" satellite

\footnotetext{
${ }^{1}$ Schultz, M. G., Pulles, T., Brand, R. van het Bolscher, M., and Dalsøren, S. B.: A global data set of anthropogenic CO, NOx, and NMVOC emissions for 1960-2000, in preparation, 2008b.
}

record for 1979-2002 from the Stratospheric Aerosol and Gas Experiments I and II (SAGE I, SAGE II) by Thomason and Peter (2006) was used and interpolated/extrapolated to close remaining gaps in polar regions and around the tropopause. The extinction coefficient, asymmetry factor, and single scattering albedo of the stratospheric aerosol record were precalculated off-line using Mie theory from the aerosol surface area density, the effective aerosol radius (both obtained from the SAGE dataset), the $\mathrm{H}_{2} \mathrm{SO}_{4}$ concentration in the particle (assuming an average constant value of $70 \mathrm{wt} \%$ ) and a mean stratospheric temperature distribution (obtained from an older SOCOL vs1.0 simulation). Tropospheric aerosols were prescribed using a climatology, described by Lohmann et al. (1999) and were used for the calculation of the local heating rates and of the shortwave backscatter. However, note that they were not used to account for aerosol cloud-interactions or for heterogeneous chemistry. The dry and wet deposition velocities of $\mathrm{O}_{3}, \mathrm{CO}, \mathrm{NO}, \mathrm{NO}_{2}, \mathrm{HNO}_{3}$, and $\mathrm{H}_{2} \mathrm{O}_{2}$ were prescribed for different types of surfaces following Hauglustaine et al. (1994). Photolysis rates and solar irradiance data used in the radiation module (monthly means) were based on Lean et al. (2000) and Haberreiter et al. (2005). In contrast to SOCOL vs1.0, SOCOL vs1.1 and beyond also include the quasi-biennial oscillation (QBO). The QBO is described based on zonal wind profiles measured near the equator at Gan/Maledives (1967-1975) and Singapore (1975-2000), see Labitzke et al. (1982). These data were used to nudge the QBO according to Giorgetta (1996).

The initial conditions for the meteorological fields were taken from the standard MA-ECHAM4 restart field, representing the state of the atmosphere in January 1988. The initial fields for all chemical species were taken from an 8year long steady state run of the MEZON CTM in the off-line mode with lower boundary conditions of the source gases for 1968. We analyse the results starting from 1979 after a 4year long coupled model spin-up.

\section{Modifications applied to SOCOL vs1.1}

The new model version SOCOL vs2.0 results from several fundamental modifications that have been applied to SOCOL vs1.1 concerning halogen chemistry, the transport scheme, and the parameterisation of water vapour. Table 1 gives a summary of the differences between SOCOL vs1.0 and SOCOL vs2.0. All modifications were performed step by step, represented by the model sub-versions SOCOL vs1.2 to vs1.5. In vs1.2, the halogen chemistry was modified, and in vs1.3-vs1.5, the transport scheme was changed. The difference between vs 2.0 and vs 1.5 is an improved parameterisation of condensation of water vapour by the highest cirrus clouds.

Although species are transported individually in vs 2.0 , the nitrogen, chlorine and bromine families are used to modify the mass fixer. In this paper they are defined by molecular number densities as follows: 
Table 1. Sub-versions of SOCOL from vs1.0 to vs 2.0 discussed in this work.

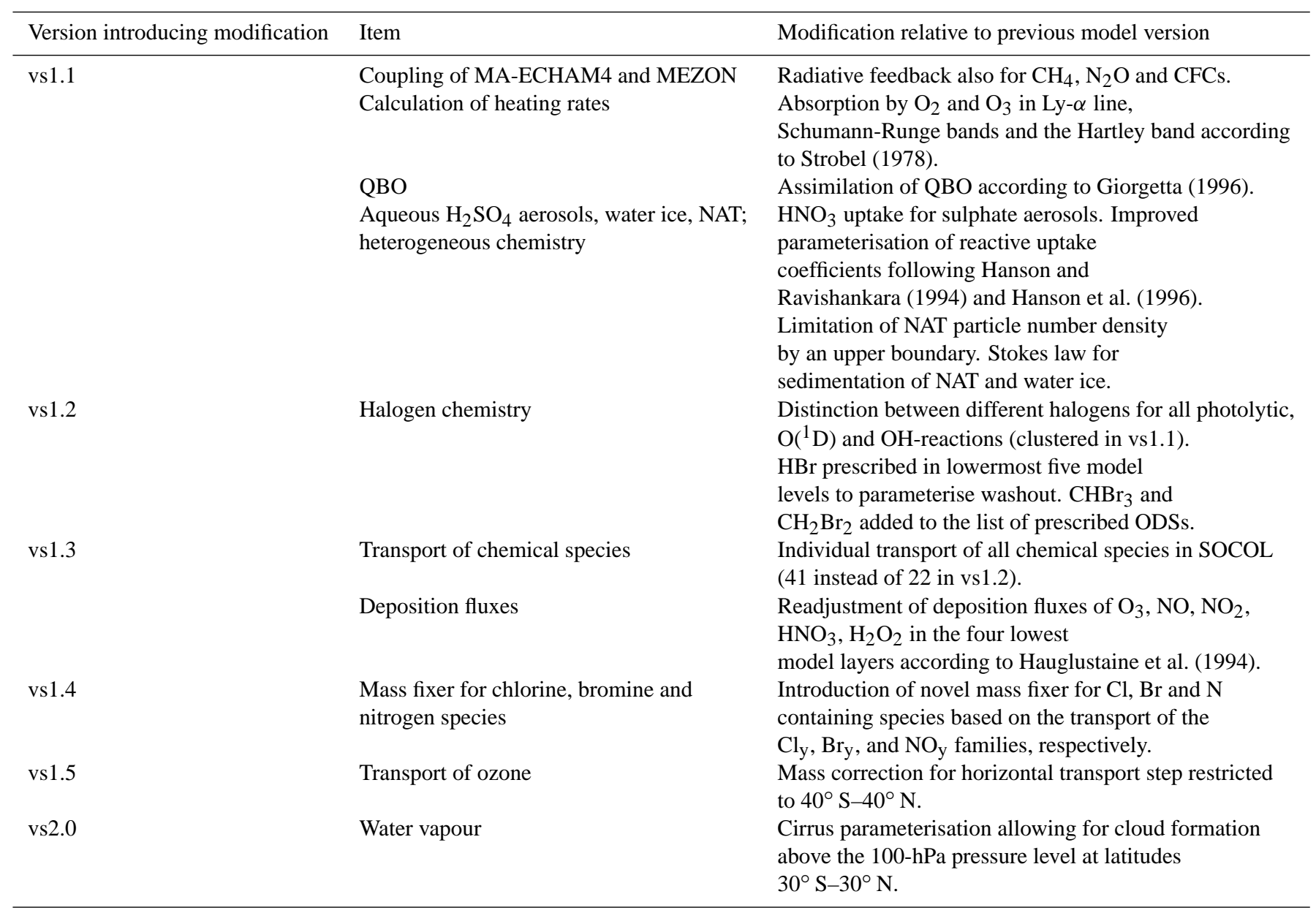

$\left[\mathrm{NO}_{\mathrm{X}}\right]=[\mathrm{N}]+[\mathrm{NO}]+\left[\mathrm{NO}_{2}\right]+\left[\mathrm{NO}_{3}\right]+2\left[\mathrm{~N}_{2} \mathrm{O}_{5}\right]+\left[\mathrm{HNO}_{4}\right]$

$\left[\mathrm{NO}_{\mathrm{y}}\right]=\left[\mathrm{NO}_{\mathrm{x}}\right]+\left[\mathrm{HNO}_{3}\right]+\left[\mathrm{ClONO}_{2}\right]+\left[\mathrm{BrONO}_{2}\right]+[\mathrm{NAT}]$

$\left[\mathrm{ClO}_{\mathrm{x}}\right]=[\mathrm{Cl}]+[\mathrm{ClO}]+[\mathrm{HOCl}]+2\left[\mathrm{Cl}_{2}\right]+2\left[\mathrm{Cl}_{2} \mathrm{O}_{2}\right]+[\mathrm{BrCl}]$

$\left[\mathrm{Cl}_{\mathrm{y}}\right]=\left[\mathrm{ClO}_{\mathrm{x}}\right]+[\mathrm{HCl}]+\left[\mathrm{ClONO}_{2}\right]$

$\left[\mathrm{CCl}_{\mathrm{y}}\right]=\left[\mathrm{Cl}_{\mathrm{y}}\right]+[\mathrm{Cl}-$ containing ODS $]$

$\left[\mathrm{Br}_{\mathrm{y}}\right]=[\mathrm{Br}]+[\mathrm{BrO}]+[\mathrm{HBr}]+[\mathrm{HOBr}]+\left[\mathrm{BrONO}_{2}\right]+[\mathrm{BrCl}]$

$\left[\mathrm{CBr}_{\mathrm{y}}\right]=\left[\mathrm{Br}_{\mathrm{y}}\right]+[\mathrm{Br}-$ containing ODS $]$,

where [NAT] is the number of $\mathrm{HNO}_{3}$ molecules per air volume condensed inside NAT particles.

The different model versions are described in the following sub-sections.

\subsection{Halogen chemistry (SOCOL vs1.2)}

In SOCOL vs1.1 the ozone destroying substances (ODS) were grouped into three families: short-lived and longlived organic chlorine containing species, as well as organic bromine containing species. Each of these families was treated as a single species in the chemistry module, using the reaction coefficients of CFC-11, CFC-12, and H1301, respectively. This simplification led to a too slow destruction of the other family members, their lifetime being shorter than the family representing ones. Consequently, the conversion to inorganic chlorine and bromine was underestimated resulting in too low concentrations of the latter families in the lower stratosphere.

Halogen chemistry in SOCOL vs1.2 is treated more comprehensively by adding 13 photolytic, $14 \mathrm{O}\left({ }^{1} \mathrm{D}\right)$-based, and 8 $\mathrm{OH}$-based oxidation reactions of the type 

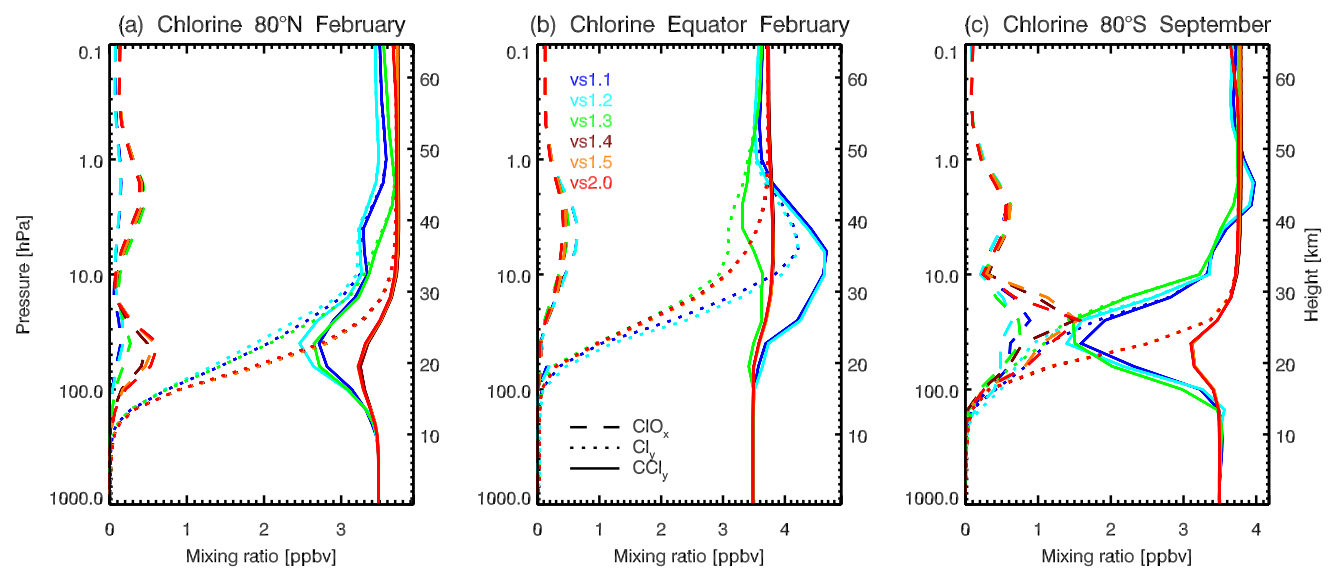

(d) Chlorine $50 \mathrm{hPa}$ February
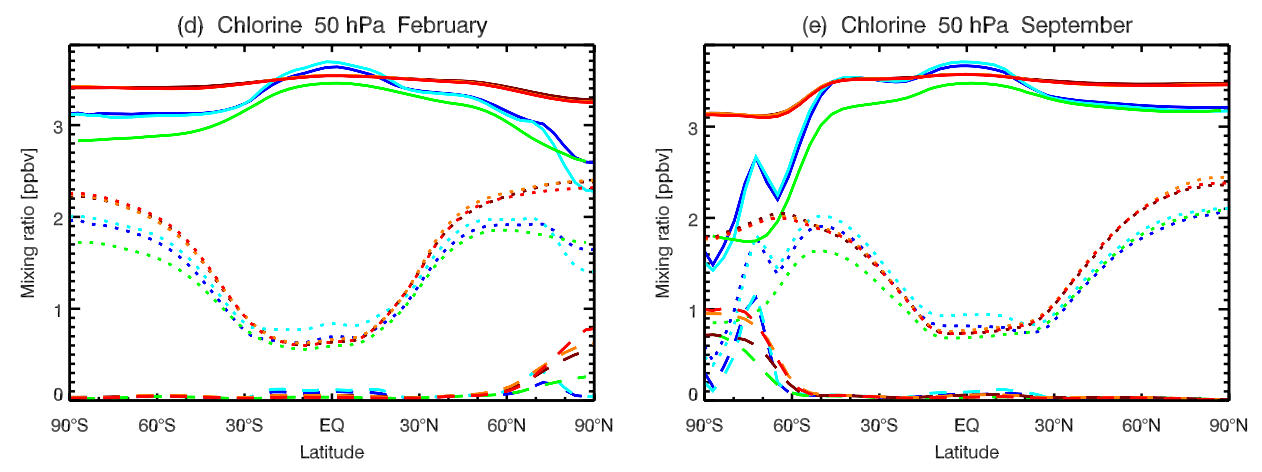

Fig. 1. Zonal mean mixing ratios of total inorganic plus organic chlorine $\mathrm{CCl}_{\mathrm{y}}$ (solid), total inorganic chlorine $\mathrm{Cl}_{\mathrm{y}}$ (dotted) and odd chlorine $\mathrm{ClO}_{x}$ (dashed) averaged over 1990-1999. The different colours indicate the different model versions as indicated in the upper centre panel (note that vs1.4 and vs1.5 are often hidden below vs.2). Vertical profiles at (a) $80^{\circ} \mathrm{N}$ in February, (b) $0^{\circ}$ in February, and (c) $80^{\circ} \mathrm{S}$ in September. Latitudinal cross sections at $50 \mathrm{hPa}$ in (d) February and (e) September.

$\mathrm{ODS}_{i}+\mathrm{h} v \rightarrow$ products

$\mathrm{ODS}_{i}+\mathrm{O}\left({ }^{1} \mathrm{D}\right) \rightarrow$ products

$\mathrm{ODS}_{i}+\mathrm{OH} \rightarrow$ products

$\left(\mathrm{ODS}_{i}=\mathrm{CFC}-11, \quad \mathrm{CFC}-12, \mathrm{CFC}-113, \mathrm{CFC}-114, \mathrm{CFC}-\right.$ $115, \mathrm{CCl}_{4}, \mathrm{CH}_{3} \mathrm{CCl}_{3}, \mathrm{HCFC}-22, \mathrm{HC}-141 \mathrm{~b}, \mathrm{HC}-142 \mathrm{~b}$, $\mathrm{H} 1211, \mathrm{H} 1301, \mathrm{CH}_{3} \mathrm{Cl}, \mathrm{CH}_{3} \mathrm{Br}, \mathrm{CHBr}_{3}$, and $\mathrm{CH}_{2} \mathrm{Br}_{2}$ ) resulting in an individual chemical treatment of all ODS species in the model. However, to save computational costs the individual treatment of ODS substances is not applied to transport, but the family members are partitioned after each transport step in each grid cell. The fraction $P_{i}$ of each family member is estimated by the age of air $t_{\text {air }}$, the (prescribed) concentration of the substance in the planetary boundary layer $c_{i}^{b c}$, the number of chlorine and bromine atoms $n_{i}$, respectively, and the lifetime of the substance $\tau_{c_{i}}$ :

$P_{i}:=\frac{n_{i}\left[c_{i}^{b c}\right] e^{-\frac{t_{\text {air }}}{\tau_{c_{i}}}}}{\sum_{j=1}^{n} n_{j}\left[c_{j}^{b c}\right] e^{-\frac{t_{\mathrm{air}}}{\tau_{c_{j}}}}}$
The age of air is parameterised to match model results of a tracer study with MA-ECHAM4 (Manzini and Feichter, 1999): The atmosphere is divided into 5 sections, assuming a constant value of age of air in each of these sections. The only time dependence is reflected by the online calculation of the local tropopause height according to WMO (1957), which separates the two lowermost sections.

For $\mathrm{HBr}$, a lower boundary condition is introduced in vs 1.2 to parameterise tropospheric washout: In the lowermost five model layers, $\mathrm{HBr}$ is prescribed to amount to $0.1 \mathrm{pptv}$. In vs1.1, where no lower boundary condition existed, $\mathrm{HBr}$ was artificially accumulated in the whole troposphere. Besides, the organic bromine species bromoform $\left(\mathrm{CHBr}_{3}\right)$ and methylene bromide $\left(\mathrm{CH}_{2} \mathrm{Br}_{2}\right)$ have been added in vs1.2 such that the model now treats 16 different ODSs.

Figure 1 shows the 1990-1999 zonal mean values of $\mathrm{ClO}_{\mathrm{x}}$, $\mathrm{Cl}_{\mathrm{y}}$, and $\mathrm{CCl}_{\mathrm{y}}$ for the different model versions. In general, differences between vs1.1 and vs1.2 are small. The unrealistic features described in Sect. 1 are visible in both model versions: while total chlorine $\left(\mathrm{CCl}_{\mathrm{y}}\right)$ is expected to display an almost constant profile (with small deviations possibly caused by the time-dependent input of ODS), the simulated stratospheric $\mathrm{CCl}_{\mathrm{y}}$ in the tropics is up to $30 \%$ higher 

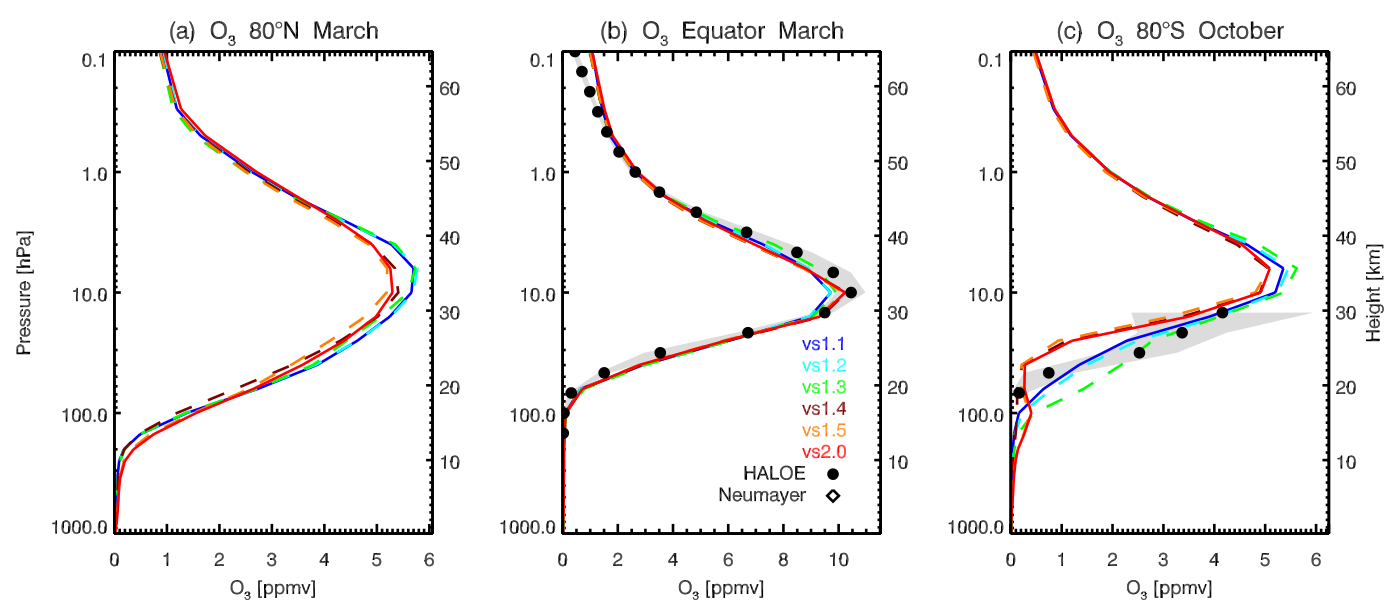

(d) $\mathrm{O}_{3} 50 \mathrm{hPa}$ March
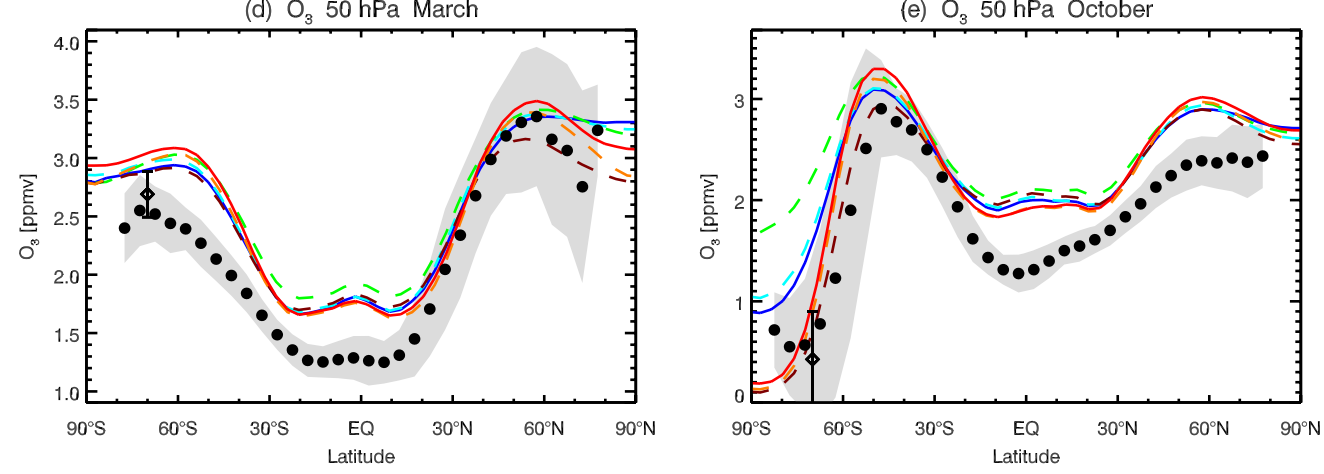

Fig. 2. Zonal mean mixing ratios of ozone averaged over 1990-1999. The different colours indicate the different model versions as indicated in the upper centre panel. Black bullets: HALOE observations; grey area: HALOE \pm 1 standard deviation $(\sigma)$ about the climatological zonal mean. Profiles at (a) $80^{\circ} \mathrm{N}$ in March, (b) $0^{\circ}$ in March, and (c) $80^{\circ} \mathrm{S}$ in October. Latitudinal cross sections at $50 \mathrm{hPa}$ in (d) March and (e) October.

than the maximum tropospheric $\mathrm{CCl}_{\mathrm{y}}$ in vs1.1 and vs1.2 (Fig. 1b). This feature also appears at high latitudes of both hemispheres during spring and summer, but there it is limited to the upper stratosphere (Fig. 1c, not shown for the Northern Hemisphere). During winter and spring, unrealistic $\mathrm{CCl}_{\mathrm{y}}$ minima centred at $50 \mathrm{hPa}$ appear at high latitudes, most prominent over Antarctica with values about 50\% lower than in the upper stratosphere (Fig. 1a, c, d, e). Another obviously artificial feature is the peak in $\mathrm{CCl}_{\mathrm{y}}$ at the edge of the Southern polar vortex (Fig. 1e).

In contrast to chlorine, bromine species are significantly different between vs1.2 and vs1.1. Due to the newly introduced tropospheric $\mathrm{HBr}$ sink, both inorganic bromine $\left(\mathrm{Br}_{\mathrm{y}}\right)$ and total inorganic and organic bromine $\left(\mathrm{CBr}_{\mathrm{y}}\right)$ are considerably lower in vs 1.2 compared to vs $1.1(30-80 \%$ in the middle and lower stratosphere, $>95 \%$ in the troposphere) (not shown). The artificial accumulation of $\mathrm{HBr}$ in the troposphere and lowermost stratosphere present in vs1.1 disappears in vs1.2.

Figures 2 and 3 show zonal means of ozone mixing ratio and column (total ozone), respectively, averaged over the period 1990-1999 for the various model versions in com- parison with satellite observations. Slightly higher inorganic chlorine and considerably reduced bromine concentrations in vs1.2 compared to vs1.1 result in 15-30\% higher ozone abundance in the troposphere (not shown), but have negligible effects in the stratosphere (Fig. 2), except under volcanic conditions, when ozone in the lower tropical stratosphere is reduced by $5-15 \%$ (not shown). Total ozone is enhanced by $2-5 \%$ in vs 1.2 compared to vs1.1 with a maximum increase over Antarctic in early spring (Fig. 3).

\subsection{Transport of all species (SOCOL vs1.3)}

To save computational costs, the very short lived species were not transported in SOCOL vs1.0-1.2. However, some of the species not transported, such as $\mathrm{ClO}$ or $\mathrm{Cl}_{2} \mathrm{O}_{2}$, led to artificial accumulations in abundance as, for example, it is seen at the edge of the Southern polar vortex at $70^{\circ} \mathrm{S}$ by a peak in $\mathrm{CCl}_{\mathrm{y}}$ (Fig. 1e). In SOCOL vs1.3, the number of transported species has been increased by 19 substances $(\mathrm{Cl}, \mathrm{ClO}, \mathrm{HOCl}$, $\mathrm{Cl}_{2} \mathrm{O}_{2}, \mathrm{Br}, \mathrm{HBr}, \mathrm{HOBr}, \mathrm{N}, \mathrm{NO}_{3}, \mathrm{H}, \mathrm{OH}, \mathrm{HO}_{2}, \mathrm{CH}_{3}, \mathrm{CH}_{3} \mathrm{O}$, $\mathrm{CH}_{3} \mathrm{O}_{2}, \mathrm{CH}_{2} \mathrm{O}, \mathrm{HCO}, \mathrm{CH}_{3} \mathrm{O}_{2} \mathrm{H}, \mathrm{O}\left({ }^{1} \mathrm{D}\right)$ ), so that now all 41 species of SOCOL are transported individually. However, 
(a) vs1.1

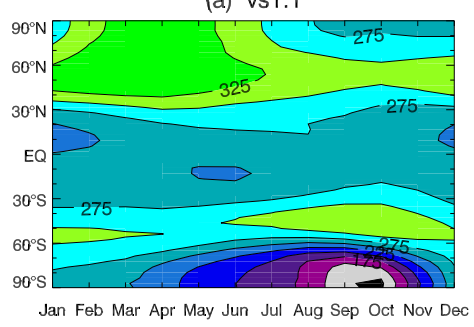

(d) v1s.4

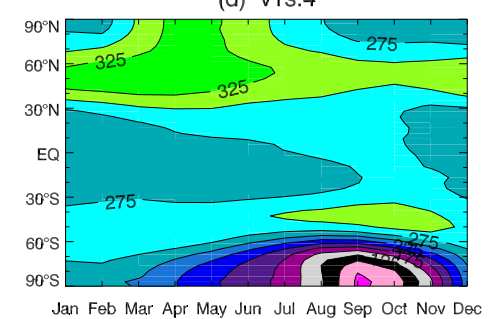

(g) NIWA

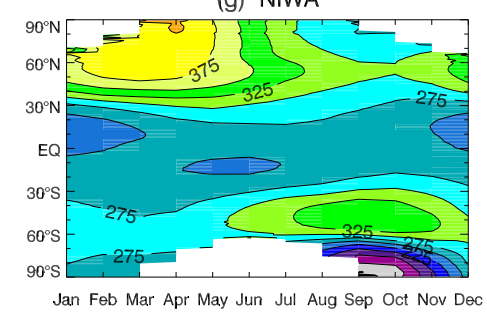

(b) vs1.2

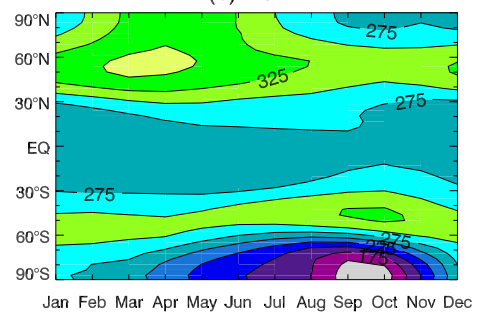

(e) vs1.5

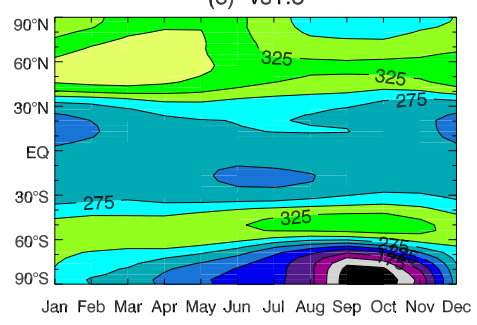

(c) vs1.3

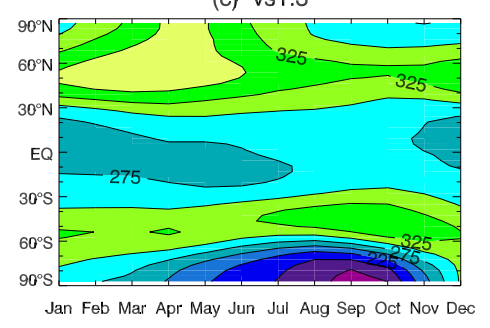

(f) vs2.0

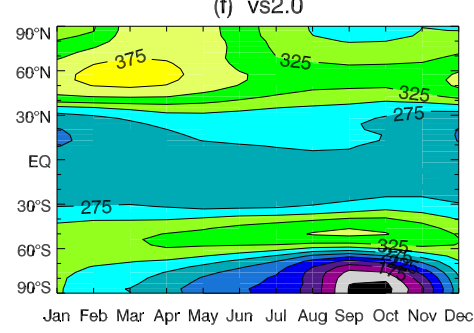

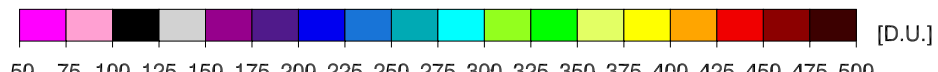

5075100125150175200225250275300325350375400425450475500

Fig. 3. Zonal mean of total ozone column in Dobson Units (D.U.) averaged over 1990-1999. (a)-(f) Simulated data for different model versions, (g) NIWA observational data.

the individual transport of all members of the nitrogen, chlorine, or bromine families by a transport scheme that is not mass-conservative requires the application of special measures, such as a family-based mass fixing procedure, to establish mass conservation of the family itself both globally and regionally. Family-based mass fixing has been introduced to SOCOL in vs1.4 and will be discussed in Sect. 4.3.

In vs1.3, both the accumulation of total chlorine $\left(\mathrm{CCl}_{\mathrm{y}}\right)$ in the middle and upper stratosphere (Fig. 1b, 1c) and the peak in $\mathrm{CCl}_{\mathrm{y}}$ at the edge of the polar vortex at $70^{\circ} \mathrm{S}$ in winter/early spring (Fig. 1e) disappear (green curves). However, transporting all species has no effect on the minimum of $\mathrm{CCl}_{\mathrm{y}}$ at $50 \mathrm{hPa}$ at high latitudes in late winter/early spring. The reduction of $\mathrm{ClO}_{\mathrm{x}}$ (and $\mathrm{Br}_{\mathrm{y}}$, not shown) concentrations at high latitudes of the lower stratosphere in vs1.3 compared to vs1.2 result in less efficient chlorine and bromine-induced ozone destruction cycles and to ozone concentrations that are higher than observed (Fig. 2). This effect is most pronounced in the Southern polar vortex $(+40-100 \% ;>100 \%$ after the eruption of Mt. Pinatubo), see Fig. 2c, e. Compared to vs1.2, ozone is increased by 5-10\% (75-100\% after Mt. Pinatubo for about two years) in the tropical lower stratosphere and by $5 \%$ in the upper stratosphere. Total ozone is increased by $5-10 \%$ in the tropics and middle latitudes and by $20 \%$ (>50\% after Mt. Pinatubo) at the Southern high latitudes in late winter/early spring (Fig. 3).

\subsection{Family-based mass fixing (SOCOL vs1.4)}

As already stated above, the total chlorine minimum apparent at high latitudes at $50 \mathrm{hPa}$ in late winter/early spring remains even when all species are transported (Fig. 4a). While mass conservation is checked and ensured locally after each chemistry time step, the minimum results from mass loss of $\mathrm{CCl}_{\mathrm{y}}$ (or total bromine, $\mathrm{CBr}_{\mathrm{y}}$ ) at high latitudes after the application of the mass fixer correcting for the violation of mass conservation by the transport scheme, as it will be explained in the following.

The transport of chemical species in SOCOL is calculated using the hybrid numerical advection scheme of Zubov et al. (1999), which is a combination of the Prather scheme in flux form (Prather, 1986) for vertical transport and a semiLagrangian scheme (Ritchie, 1985; Williamson and Rasch, 1989) for horizontal transport. The Prather scheme is strictly mass conservative and ensures to maintain strong gradients (Prather, 1986). However, since the Courant-FriedrichsLewy (CFL) stability condition (Courant et al., 1928) has to 


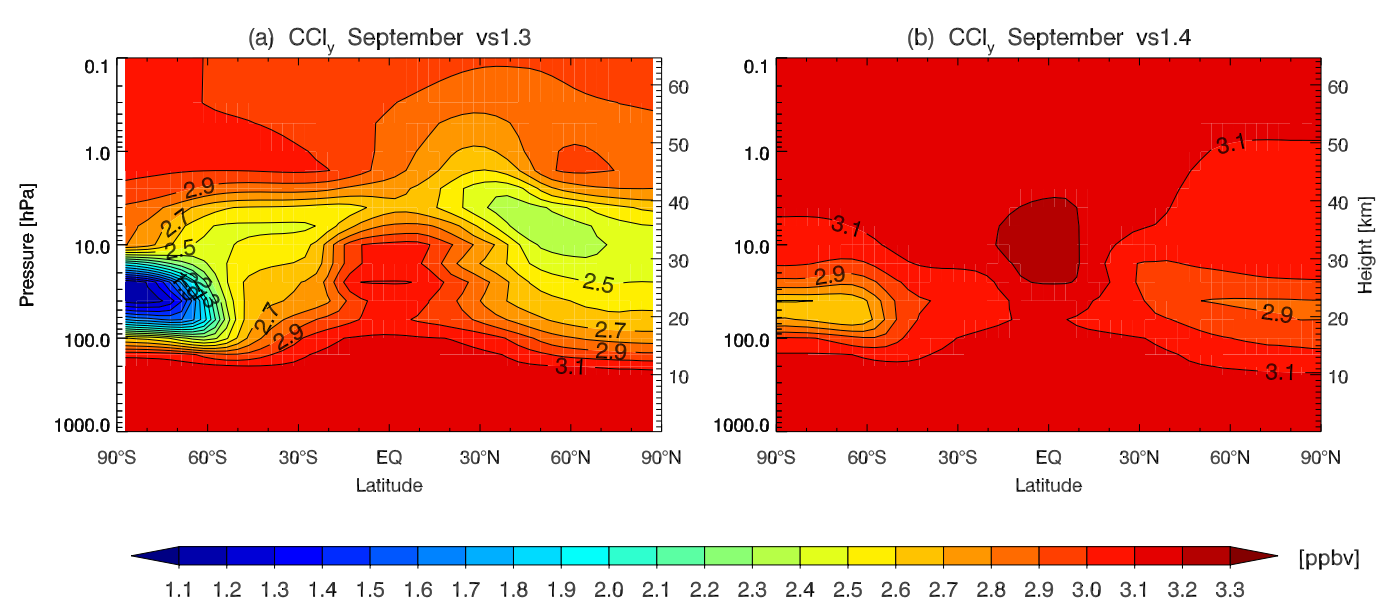

Fig. 4. Modeled zonal mean mixing ratio of total organic plus inorganic chlorine $\left(\mathrm{CCl}_{\mathrm{y}}\right)$ in September for (a) vs1.3 and (b) vs1.4. Means calculated for the period 1985-1990.

Table 2. Sensitivity model runs performed to overcome the problem of artificial chlorine loss at high latitudes.

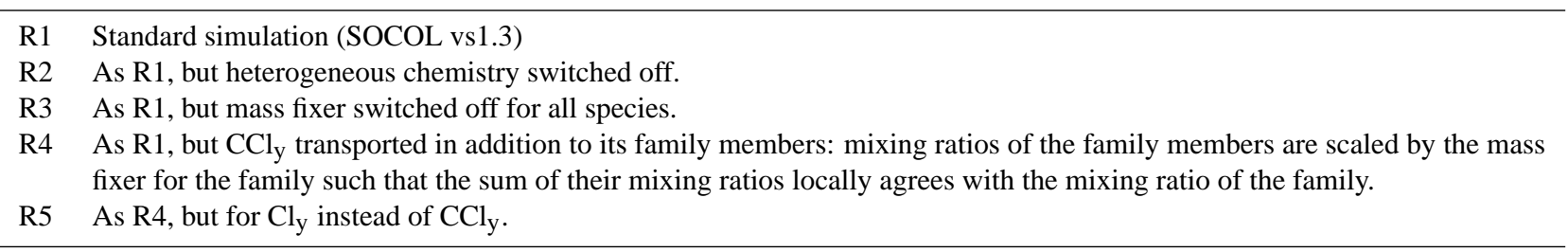

be satisfied, it is computationally expensive. Therefore, the Prather scheme is only used to calculate the transport in the vertical direction. For the semi-Lagrangian scheme, which is used to calculate the horizontal transport on each model layer, the CFL criterion does not need to be fulfilled. This enables precise treatment of transport near the poles with large time steps (two hours in SOCOL). However, in contrast to the Prather scheme, the semi-Lagrangian scheme is not mass conservative. For this reason a so-called mass fixer has to be used to guarantee conservation of total mass of each species in each model layer. After each transport step, the transport error

$$
\Delta m_{s}(k)=\sum_{i, j} m_{s, A}(i, j, k)-\sum_{i, j} m_{s, B}(i, j, k)
$$

is calculated for every model layer $k$ and every species $s$, where $m_{s, B}(i, j, k)$ and $m_{s, A}(i, j, k)$ are the mass of $s$ in the grid box $(i, j, k)$ before and after the horizontal transport step, respectively. Then, $\Delta m_{s}(k)$ is used to scale the mixing ratios of the species $\mu_{s, A}(i, j, k)$ calculated by the semiLagangian scheme. Note that the mass fixer applied in SOCOL does not correct the individual grid boxes of a layer uniformly, but proportionally to $\left|\mu_{s, A}(i, j, k)-\mu_{s, B}(i, j, k)\right|^{3 / 2}$ (Williamson and Rasch, 1989) to penalise regions with steep horizontal gradients (which are more critical for errors than regions with almost uniform distributions). Finally, by design, the fixer enables mass conservation only of a whole horizontal layer, but not of individual geographic regions. This may lead to artificial horizontal mass transport and artificial mass loss or accumulation in particular regions. Using the mass fixer of Williamson and Rasch (1989) in SOCOL, regions with steeper horizontal gradients, such as the region of the polar vortex, experience larger corrections and are therefore more vulnerable to artificial mass loss or accumulation.

To better understand the role of the mass fixer for the Southern polar vortex region, we performed idealized tracer simulations with SOCOL vs1.3 using two reciprocally distributed tracers. As initial fields of the simulation, tracer 1 was defined to have a mixing ratio of unity from the South Pole to $83^{\circ} \mathrm{S}$ and a mixing ratio of zero between $69^{\circ} \mathrm{S}$ and the North Pole. Between $83^{\circ} \mathrm{S}$ and $69^{\circ} \mathrm{S}$, the mixing ratio dropped linearly from one to zero. As initial condition for tracer 2, the opposite distribution was used such that the sum of both tracers was unity at all latitudes. The same latitudinal distribution was applied to all altitudes for both tracers. The simulation was started on 1st of September 1996. After one month, the sum of the two tracers, which should ideally remain one everywhere, was found to decrease to about 0.9 in the polar region. We repeated the same simulation with reduced time step and with exponents of 0 or 1 for the mass 
(a) $\mathrm{CCl}_{\mathrm{y}} 50 \mathrm{hPa} 80^{\circ} \mathrm{S}$

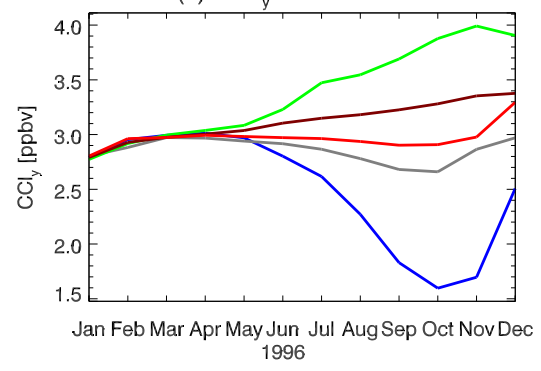

(b) $\mathrm{Cl}_{\mathrm{y}} 50 \mathrm{hPa} 80^{\circ} \mathrm{S}$

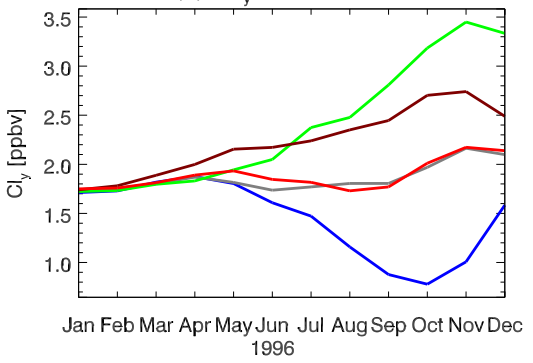

(c) $\mathrm{O}_{3} 50 \mathrm{hPa} 80^{\circ} \mathrm{S}$

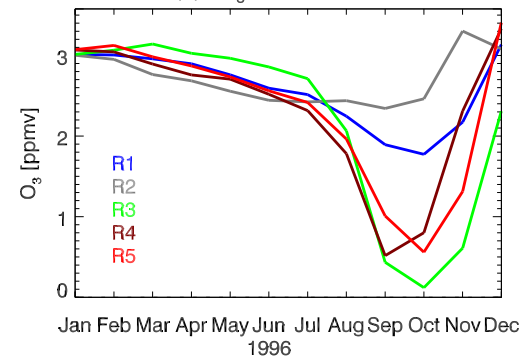

Fig. 5. Seasonal variations of mixing ratios of (a) total organic and inorganic chlorine $\mathrm{CCl}_{\mathrm{y}}$ in ppbv, (b) total organic chlorine $\mathrm{Cl}_{\mathrm{y}}$ in ppbv, and (c) ozone in ppmv at $50 \mathrm{hPa}$ and $80^{\circ} \mathrm{S}$ for the sensitivity simulations described in Table 2 . All simulations start at 1 January 1996 and are based on SOCOL vs1.3.

fixer instead of $3 / 2$ as in Williamson and Rasch (1995). However, the artificial mass loss was found not to improve in these experiments. Next, we used bilinear instead of Hermite's spline interpolation to compute the values of the transported gas mixing ratios at the so-called "departure" points of the semi-Lagrangian scheme. This improved the conservation of mass, but led to an undesirable enhancement of numerical diffusion.

Several sensitivity tests were performed to investigate the effects of the mass fixer on chlorine and ozone (all starting 1st January 1996). Table 2 gives an overview over the sensitivity simulations carried out, and Fig. 5 shows their effects on total chlorine $\left(\mathrm{CCl}_{\mathrm{y}}\right)$, inorganic chlorine $\left(\mathrm{Cl}_{\mathrm{y}}\right)$, and ozone at $50 \mathrm{hPa}$ and $80^{\circ} \mathrm{S}$. When heterogeneous chemistry is switched off (R2), the artificial mass loss of $\mathrm{CCl}_{\mathrm{y}}$ and $\mathrm{Cl}_{\mathrm{y}}$ is considerably reduced. Hence, there is strong indication that this effect is caused by the members of the active chlorine family $\left(\mathrm{ClO}_{\mathrm{x}}\right)$ with steep gradients at the vortex edge. Switching off the mass fixer completely (R3) leads to massive increases in $\mathrm{CCl}_{\mathrm{y}}$ and $\mathrm{Cl}_{\mathrm{y}}$ (Fig. 5a, b) resulting from artificial mass accumulation. From September to December, polar ozone in R3 is considerably lower compared to R1 mainly because of the artificially accumulated $\mathrm{Cl}_{\mathrm{y}}$ (Fig. 5c). Simulations $\mathrm{R} 4$ and $\mathrm{R} 5$ show how mass conservation of $\mathrm{CCl}_{\mathrm{y}}$ and $\mathrm{Cl}_{\mathrm{y}}$ can be improved. In these simulations, either $\mathrm{CCl}_{\mathrm{y}}(\mathrm{R} 4)$ or $\mathrm{Cl}_{\mathrm{y}}$ (R5) is transported in addition to the individual family members. The mass fixer of Williamson and Rasch is not applied to the individual family members, but to the transported family instead. Finally, in every grid box the mixing ratio of the transported and mass-corrected family $[f]_{T}^{*}$ is used to re-scale the mixing ratios of the transported family members $\left[c_{i}\right]_{T}$ such that the sum of their mixing ratios matches the mixing ratio of the family locally:

$\left[c_{i}\right]_{T}^{*}=\frac{[f]_{T}^{*}}{\sum_{j=1}^{N} n_{j}\left[c_{j}\right]_{T}}\left[c_{i}\right]_{T}$

The suffix * depicts mass correction after semi-Lagrangian transport $T, n_{i}$ the number of chlorine atoms of the family member $c_{i}$, and $N$ the total number of family members. Ba- sically, this procedure re-introduces a local component to the mass fixer that the standard procedure cannot provide. By applying this method $\mathrm{CCl}_{\mathrm{y}}\left(\mathrm{Cl}_{\mathrm{y}}\right)$ is nearly conserved for $\mathrm{R} 4$ (R5), as can be seen from Fig. $5 \mathrm{a}$ and $5 \mathrm{~b}\left(\mathrm{CCl}_{\mathrm{y}}\left(\mathrm{Cl}_{\mathrm{y}}\right)\right.$ slightly increases in time, since the model spins-up during the first model year). Figure $5 \mathrm{c}$ shows that polar ozone at $50 \mathrm{hPa}$ is substantially lower in late winter and spring (and thus much more realistic) for R4 and R5 compared to R1 as a result of increased chemical ozone destruction due to higher $\mathrm{Cl}_{\mathrm{y}}$ concentrations.

In SOCOL vs1.4 we applied the R5 method to obtain mass conservation of the chlorine containing species (we did not make use of R4 to avoid conversion of organic chlorine to inorganic chlorine and vice versa). Similarly, family-based mass fixing is used for the bromine and the nitrogen families. For ozone however, since no corresponding family exists, this method cannot be applied.

Figure 4 puts this method to test by showing the climatological mean of $\mathrm{CCl}_{\mathrm{y}}$ in September. Compared to vs1.3 (Fig. 4a), the artificial mass loss in the region of the southern polar vortex is considerably reduced in vs1.4, but still present to a minor degree (since family-based mass fixing is only applied to inorganic chlorine, $\mathrm{Cl}_{\mathrm{y}}$, not to total chlorine, $\mathrm{CCl}_{\mathrm{y}}$ ). Another deficiency remains with $\mathrm{CCl}_{\mathrm{y}}$ being slightly higher in the middle and upper stratosphere than in the troposphere, especially in the tropics. As the fields in Fig. $4 \mathrm{~b}$ are averaged over 1985-1990, when anthropogenic CFC emissions were still increasing, the opposite vertical dependence would be expected. The problem is likely caused by some remaining artificial mass transport of $\mathrm{CCl}_{\mathrm{y}}$ from high latitudes to the tropics in the lower stratosphere in late winter/early spring. Via the tropical pipe, this error is transported to the middle and upper stratosphere.

In spite of the remaining shortcomings, the distribution of chlorine is much more realistic in vs1.4 than in vs1.3, which is also evident from Fig. 1. As a result of family-based mass fixing, in vs $1.4 \mathrm{CCl}_{\mathrm{y}}$ is increased by $15-25 \%$ in the upper and middle stratosphere, as well as in the tropical lower stratosphere (Fig. 1b), and by more than $100 \%$ in the region of 


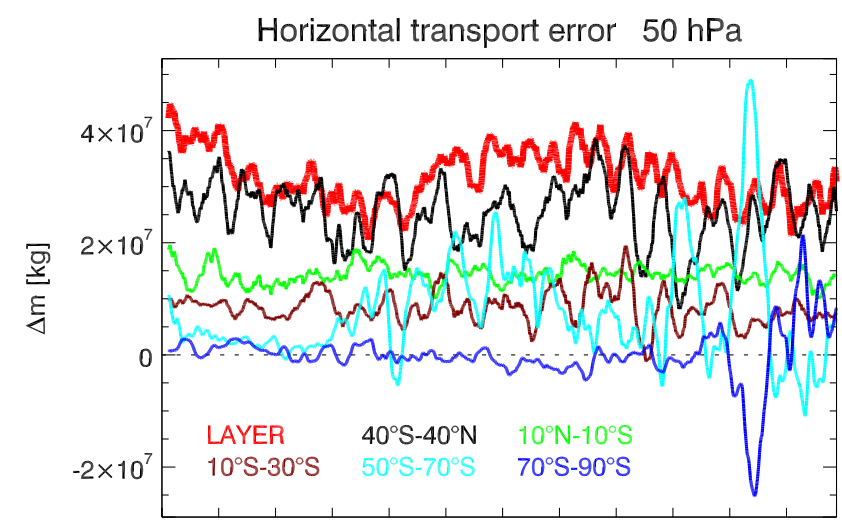

Jan Feb Mar Apr May Jun Jul Aug Sep Oct Nov Dec 1996

Fig. 6. Evolution of the transport error in ozone mass (in $\mathrm{kg} \mathrm{O}_{3}$ ) after each horizontal transport time step for the model layer at $50 \mathrm{hPa}$ in SOCOL vs1.4. Red line: total layer transport error, which determines the value of the mass fixer. Other colours: contributions to the error stemming from different latitudinal bands. Data smoothed over seven days.

the polar vortex (Fig. 1a, c-e) in comparison to vs1.3. Likewise, $\mathrm{ClO}_{\mathrm{x}}$ is enhanced by $20-120 \%$ in the polar vortex, but decreased by $15-20 \%$ in the upper stratosphere (in contrast to $\mathrm{CCl}_{\mathrm{y}}$ ), especially in the winter hemisphere. This decrease in $\mathrm{ClO}_{\mathrm{x}}$ is probably caused by an increase of $\mathrm{NO}_{\mathrm{y}}$ and $\mathrm{NO}_{\mathrm{x}}$. Through family-based mass fixing, nitrogen oxides are enhanced by $30-70 \%$ in the middle and upper stratosphere compared to vs 1.3 and reduced by $20 \%$ in the lower stratosphere, resulting in a better agreement with HALOE satellite retrievals (not shown). The low $\mathrm{NO}_{\mathrm{y}}$ and $\mathrm{NO}_{\mathrm{x}}$ abundances in the middle and upper stratosphere in vs1.3 most probably result from insufficient vertical transport of these substances within the tropical pipe (due to excessive horizontal diffusion of chemical species in the lower stratosphere away from the tropical region towards high latitudes, caused by the semiLagrangian scheme).

Family-based mass fixing also leads to a significant improvement in the distribution of total bromine $\left(\mathrm{CBr}_{\mathrm{y}}\right)$ (not shown). In vs1.3, very low mixing ratios of $\mathrm{CBr}_{\mathrm{y}}$ were found in the whole stratosphere that amounted to only 20 $30 \%$ of the tropospheric values leading to an underestimation of observed stratospheric inorganic bromine [Sinnhuber et al., 2005] by about $60 \%$. Similar as for $\mathrm{NO}_{\mathrm{y}}$ the low stratospheric $\mathrm{CBr}_{\mathrm{y}}$ abundance in vs1.3 probably resulted from artificial transport of the bromine containing species from the tropical tropopause to high latitudes by the semi-Lagrangian scheme, where they were transported back to the troposphere without having reached the middle and upper stratosphere. In vs1.4, $\mathrm{CBr}_{\mathrm{y}}$ is constant with height to a high degree, except for the region of the polar vortex, where it has a similar minimum as $\mathrm{CCl}_{\mathrm{y}}$ (not shown, for $\mathrm{CCl}_{\mathrm{y}}$ see Fig. $4 \mathrm{~b}$ ).
The changed spatial distributions of the halogens and the nitrogen oxides strongly affect ozone destruction by the catalytic cycles. As can be seen from Fig. $2 \mathrm{~d}$ and e, in vs 1.4 ozone is decreased by more than $75 \%$ compared to vs 1.3 in the regions of the polar vortices in both hemispheres and by $10 \%$ at middle latitudes of the lower stratosphere, mainly because of increased $\mathrm{ClO}_{\mathrm{x}}$ (Fig. 1). In the upper stratosphere, ozone is decreased by $10-15 \%$ because of increased $\mathrm{NO}_{\mathrm{x}}$. Total ozone is decreased by $5-15 \%$ at middle latitudes and by more than $50 \%$ in the Southern high latitudes in September and October (Fig. 3c, d). Obviously, vs1.4 total ozone is significantly more underestimated than vs1.3 compared to the New Zealand National Institute of Water and Atmospheric Research (NIWA) observational data set compiled by Bodeker (2005) in the Southern high latitudes in September and October and in the Northern middle and high latitudes in spring. Hence, while family-based mass fixing leads to a significant improvement of modelled chlorine, nitrogen and bromine, the model performance with respect to total ozone gets worse emphasizing the necessity to additionally investigate the reliability of modelled ozone transport. This will be dealt with in the next section.

\subsection{Latitudinal restriction of ozone mass fixer to $40^{\circ} \mathrm{S}-$ $40^{\circ} \mathrm{N}$ (SOCOL vs1.5)}

For ozone, the family approach described in Sect. 4.3 cannot be applied. Sensitivity tests with the mass fixer switched off for ozone revealed that modelled ozone concentrations of both hemispheres are highly influenced by the mass fixer. At middle and high latitudes in late winter/early spring, total ozone is significantly increased when the mass fixer is switched off for ozone (not shown) indicating that the too low column ozone values in these regions (Fig. 3d) are at least partly caused by the mass fixer. Qualitatively, the pattern of latitudinal and seasonal variability of zonal mean total ozone fits better with observations if the mass fixer is switched off for ozone. However, mass conservation is not provided in this case and modelled ozone accumulates artificially in large parts of the stratosphere and troposphere leading to a general overestimation of total ozone when compared to observations. Therefore a possible solution of the mass fixing problem of ozone could be to restrict mass corrections to given geographical regions still ensuring global mass conservation on a model layer, but avoiding it in other regions, where the mass fixer produces significant mass loss or accumulation. This methodology was developed based on the results of a sensitivity simulation, by which we show that those regions contributing most to the layer transport error (the global transport error of a certain model layer) are generally not identical with the regions where the mass fixer corrects most. The sensitivity simulation (vs1.4) aimed to quantify the contributions of different latitudinal regions to the layer transport error $\Delta m$ of ozone caused by the semiLagrangian horizontal transport scheme. For this purpose, 
the globe was divided into nine different latitude belts of $20^{\circ}$ width $\left(70^{\circ} \mathrm{S}-90^{\circ} \mathrm{S}, 50^{\circ} \mathrm{S}-70^{\circ} \mathrm{S}\right.$ etc.). For each latitudinal belt, a corresponding tracer was defined setting its mixing ratio to the ozone value at every grid box within the belt and to a constant value (the zonal mean of ozone at the edges of the belt) elsewhere before each horizontal transport step. As the semi-Lagrangian scheme does not produce an error for constant distributions, the layer transport error $\Delta m_{i}$ caused by transport of tracer $i$ reflects the contribution of the $\mathrm{i}^{\text {th }}$ latitude belt to the layer transport error $\Delta m$ caused by transport of ozone.

Figure 6 shows the layer transport error $\Delta m$ of ozone at $50 \mathrm{hPa}$, as well as the individual contributions to this error by the tropical belt $\left(10^{\circ} \mathrm{S}-10^{\circ} \mathrm{N}\right)$, the Southern subtropical belt $\left(10^{\circ} \mathrm{S}-30^{\circ} \mathrm{S}\right)$, and the Southern high latitudinal belts $\left(50^{\circ} \mathrm{S}-70^{\circ} \mathrm{S} ; 70^{\circ} \mathrm{S}-90^{\circ} \mathrm{S}\right)$ as 7-day running mean for 1996. In addition, the transport error produced by the belt $40^{\circ} \mathrm{S}-$ $40^{\circ} \mathrm{N}$ is shown. During the whole year, the layer transport error of ozone is positive (red curve), i.e. before corrections by the mass fixer are performed, the global ozone mass in the model layer at $50 \mathrm{hPa}$ is higher after horizontal transport than before. Thus, the mass fixer continuously leads to a downward correction of the mixing ratios in all grid boxes in this model layer. As can be seen from Fig. 6, the contributions from the different latitudinal regions to the layer transport error differ in magnitude and depend strongly on season. The contributions of the tropics and subtropics are always positive and do not underlie much annual variability, they probably result from gradients at the edge of the tropical pipe. In contrast, large amplitudes occur in the layer transport errors at high Southern latitudes during November and December, most probably related to vortex breakdown. In several months, the transport error of this region is negative indicating that corrections by the mass fixer, based on the full layer, pull simulated ozone systematically into the wrong direction, namely to lower values. This is the main explanation for the significant underestimation of ozone in the region of the Southern polar vortex.

Figure 7 shows the monthly mean of mass fixer corrections for ozone performed after every semi-Lagrangian transport step in September 1996. Below $10 \mathrm{hPa}$, the mass fixer corrects downward, whereas above $10 \mathrm{hPa}$, the corrections are upward; the corrections are most pronounced around $200 \mathrm{hPa}$ and $1 \mathrm{hPa}$. By design of the mass fixer, those regions with the steepest horizontal gradients in every model layer are corrected most. At $200 \mathrm{hPa}$, these regions coincide with the tropopause, whereas above $100 \mathrm{hPa}$ largest corrections apply to the region of the Southern polar vortex edge. From the sensitivity calculation described above it can be shown that in late winter/early spring the mass corrections are significantly too strong at middle and high latitudes and significantly too weak in the tropics and subtropics at nearly all model layers of the middle and lower stratosphere: This can be understood by the fact that in spite of smaller gradients, the contribution from the tropics and subtropics to the layer transport error is

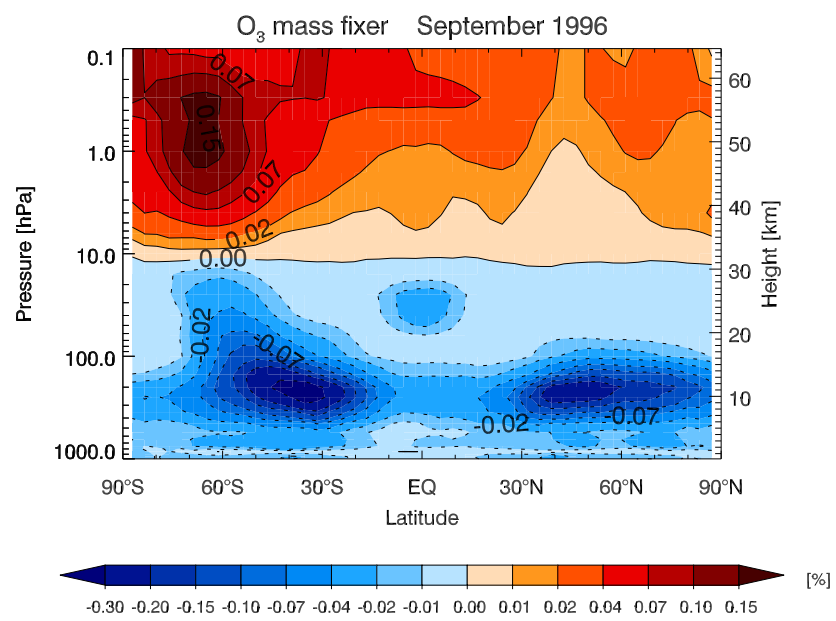

Fig. 7. Zonal mean of corrections by the mass fixer after each horizontal transport step for ozone (in \%). Monthly mean of September 1996 for SOCOL vs1.4. Positive (negative) values indicate corrections by the mass fixer towards higher (lower) concentrations.

generally larger than from middle and high latitudes, merely because the geographical extent of the tropical region (and thus the mass contained) is much larger than the area of the polar regions. In fact, the error produced by the region $40^{\circ} \mathrm{S}-$ $40^{\circ} \mathrm{N}$, which contains $\sim 60 \%$ of the area of the sphere, is responsible for the major part of the layer transport error, as shown in Fig. 6.

As consequence, in vs1.5 we restricted the mass fixer of ozone to the region $40^{\circ} \mathrm{S}-40^{\circ} \mathrm{N}$. Hence the middle and high latitudes are not affected by the mass fixer, and the overall layer transport error $\Delta m$ including mass accumulation or loss at middle and high latitudes is fully corrected in the grid boxes between $40^{\circ} \mathrm{S}$ and $40^{\circ} \mathrm{N}$, still ensuring global mass conservation on the model layers. (The mass fixing for the other species remains unchanged.) In most seasons and regions, the modelled ozone concentrations are significantly improved with this simple concept as artificial mass loss of ozone at high latitudes is avoided. However, during break-up time of the stratospheric vortices, the transport error is mainly produced at middle or high latitudes (e.g., $50^{\circ} \mathrm{S}-$ $70^{\circ} \mathrm{S}$ in November 1996, Fig. 6). Under these particular circumstances, the transport error would ideally be corrected at high latitudes and not in the tropics showing the limitations of this simple concept. In fact, the need for restricting ozone mass fixing to a certain geographical region underlines a very significant drawback to the use of semi-Lagrangian schemes for the transport of chemical species.

The restriction of ozone mass fixing to $40^{\circ} \mathrm{S}-40^{\circ} \mathrm{N}$ has a large impact on simulated ozone. In the troposphere and in the lowermost stratosphere, ozone increases by $30-100 \%$ at $40^{\circ} \mathrm{S}-90^{\circ} \mathrm{S}$ and $40^{\circ} \mathrm{N}-90^{\circ} \mathrm{N}$ and decreases by $10-30 \%$ at $40^{\circ} \mathrm{S}-40^{\circ} \mathrm{N}$. As consequence, less $\mathrm{Cl}$ is converted to $\mathrm{HCl}$ in the polar vortex, as there is more ozone to react with $\mathrm{Cl}$ to 


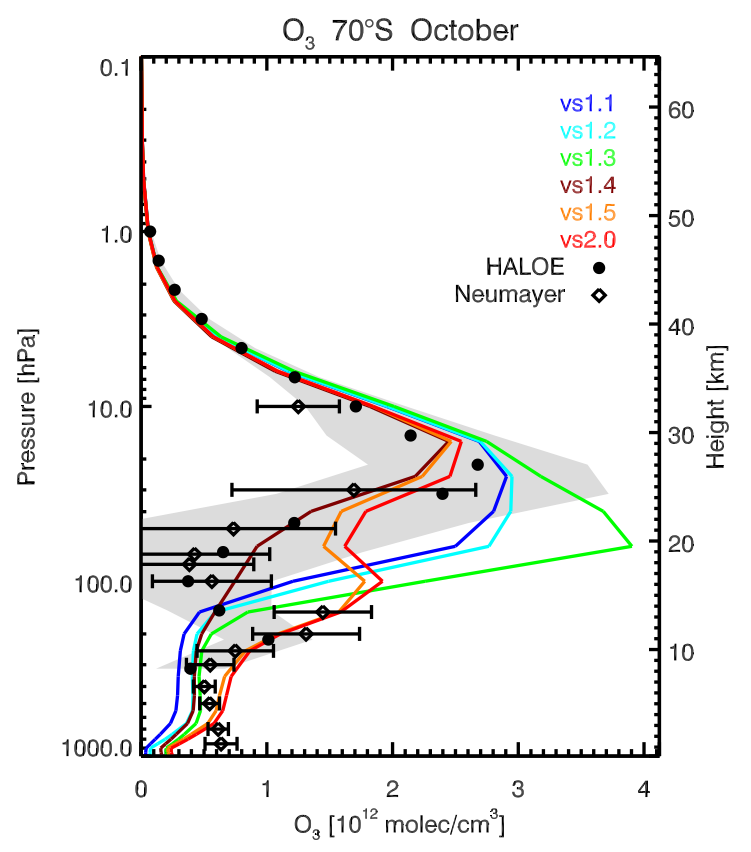

Fig. 8. Profile of zonal mean ozone number densities in $10^{12}$ molecules $/ \mathrm{cm}^{3}$ at $70^{\circ} \mathrm{S}$ in October averaged over 1990-1999. Different colours indicate the different model versions as indicated in the upper right corner. Black bullets: HALOE observations; grey area: HALOE \pm 1 standard deviation $(\sigma)$ about the climatological zonal mean. Black diamonds: balloon measurements at the German Neumayer station (Antarctica) with bars indicating \pm 1 standard deviation $(\sigma)$ about the climatological mean.

form $\mathrm{ClO}$ leading to an increase of $\mathrm{ClO}_{\mathrm{x}}$ by $40-60 \%$ compared to v1.4 (Fig. 1c, e).

Compared to the NIWA record, simulated total ozone is much improved in vs1.5, especially at high latitudes in late winter/early spring, but also in the tropics and subtropics (Fig. 3). The increase of total ozone at high latitudes in late winter/early spring in vs1.5 is mainly caused by ozone increases in the model layers below $30 \mathrm{hPa}$. Figure 8 shows mean ozone molecule number densities at $70^{\circ} \mathrm{S}$ in October for the period 1990-1999 for all SOCOL versions, as well as HALOE observations and balloon measurements at the German Neumayer station (Antarctica) over the same period of time. The observations show the well-known profile with a distinct minimum around $50 \mathrm{hPa}$. In agreement with the observations, vs 1.5 has a (less pronounced than observed) minimum at this level, in contrast to vs1.1-1.3 that showed a maximum at around $30 \mathrm{hPa}$.

\subsection{Improved treatment of water vapour (SOCOL vs2.0)}

Water vapour in SOCOL is both treated by the GCM, which includes the complete hydrological cycle in the troposphere, and by the CTM, that accounts for water vapour production/destruction by chemical reactions, but does not param- eterise condensation and gravitational settling. At altitudes below $100 \mathrm{hPa}$, the water vapour field of the CTM is taken over by the GCM (and therefore transported within MAECHAM4), whereas above this level, the water vapour field of the CTM is used in the radiation scheme of the GCM and transported like a regular chemical species in the CTM. In contrast to vs1.0-1.5, vs2.0 takes into account that clouds can also form above $100 \mathrm{hPa}$ in the tropics. In vs2.0, between $30^{\circ} \mathrm{S}$ and $30^{\circ} \mathrm{N}$ from $40 \mathrm{hPa}$ to $100 \mathrm{hPa}$, all water vapour exceeding the saturation pressure (calculated after Murphy and Koop, 2005) is removed from the system (by assuming immediate gravitational settling).

As consequence, compared to vs1.0-1.5 simulated water vapour in vs 2.0 is reduced by about $30 \%(\approx 2$ ppmv) above $100 \mathrm{hPa}$, as shown in Fig. 9. This results in a stratospheric water vapour abundance that is generally much closer to HALOE observations than in vs1.0-1.5; a relatively small negative bias is a result of a too cold tropical tropopause $(\sim 3 \mathrm{~K})$ in SOCOL. In vs2.0 the lowered stratospheric water vapour concentrations have a significant impact on stratospheric chemistry: stratospheric $\mathrm{HO}_{\mathrm{x}}$ is reduced by $15-25 \%$ leading to an increase of methane by $5 \%$ (not shown) and to an increase of ozone by $2-5 \%$ in the upper stratosphere and lower mesosphere due to a reduction of the catalytic- $\mathrm{HO}_{\mathrm{x}}$ cycle. The effect on total ozone is small (Fig. 3).

\section{Comparison with observations}

Simulated and observed ozone is shown in Fig. 2. The shapes of the simulated ozone profiles and latitudinal cross sections are in good agreement with HALOE observations with a maximum $(\sim 10 \mathrm{ppmv})$ in the tropics at about $10 \mathrm{hPa}$ (Fig. 2b). Compared to vs1.1, simulated ozone in vs 2.0 is considerably improved in the middle and high latitudes of the lower stratosphere in late winter/early spring (Fig. 2d, e). This can also be seen from Fig. 8, where ozone molecule number density is shown at $70^{\circ} \mathrm{S}$ in October. In agreement with the observations, vs1.5 and vs2.0 have a (less pronounced than observed) minimum around $50 \mathrm{hPa}$, in contrast to vs1.1-1.3 showing a maximum at $30 \mathrm{hPa}$. Compared to HALOE observations, modelled ozone is overestimated by $15-25 \%$ in the middle and high latitudes of the summer hemisphere of the lower stratosphere. In the region of the polar vortex, the bias is positive or negative depending on the month and the model layer. In the tropical lower stratosphere, simulated ozone is around $30 \%$ higher than HALOE (Fig. 2d, e), whereas in the upper stratosphere observed ozone is generally underestimated by $5-20 \%$. It is noticeable that the layers, where simulated ozone is higher (lower) than HALOE observations, coincide with the layers, where the ozone mass fixer corrects downward (upward), with the transition at about $10 \mathrm{hPa}$ (Fig. 7). It is likely that the biases in simulated ozone are at least partly connected to remaining mass transport artefacts in the semi-Lagrangian scheme. 
(a) $\mathrm{H}_{2} \mathrm{O} 80^{\circ} \mathrm{N}$ March

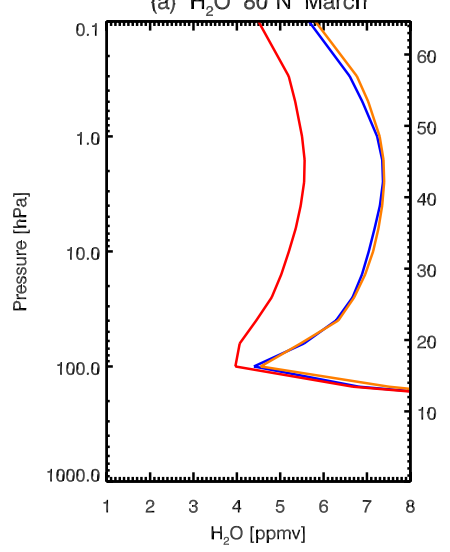

(d) $\mathrm{H}_{2} \mathrm{O} 50 \mathrm{hPa}$ March

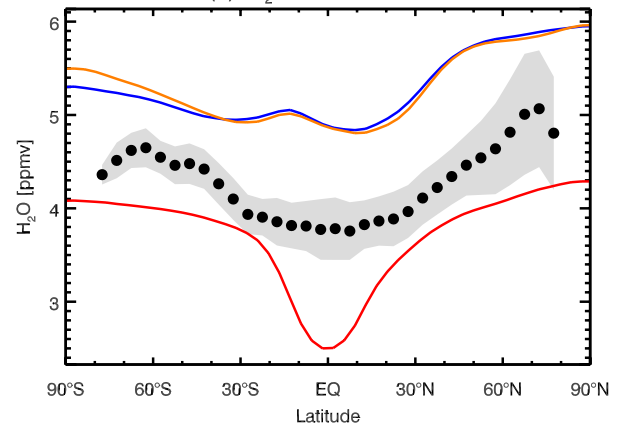

(b) $\mathrm{H}_{2} \mathrm{O}$ Equator March

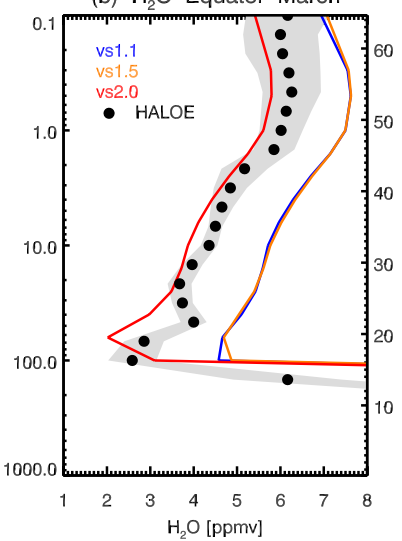

(c) $\mathrm{H}_{2} \mathrm{O} 80^{\circ} \mathrm{S}$ October

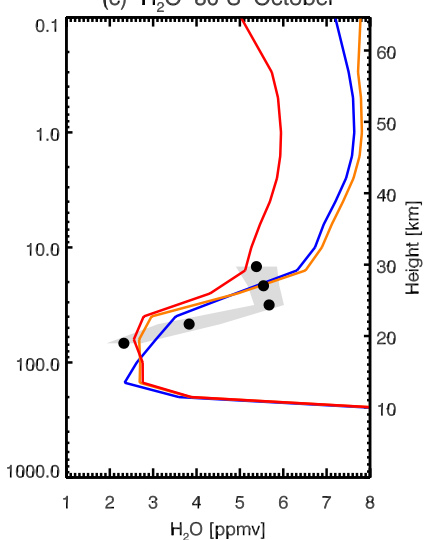

(e) $\mathrm{H}_{2} \mathrm{O} 50 \mathrm{hPa}$ October

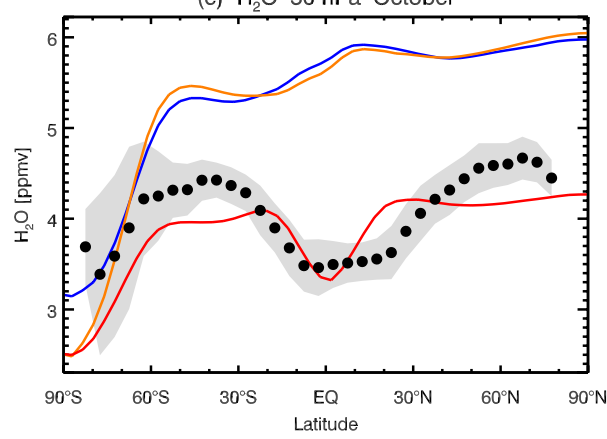

Fig. 9. Same as in Fig. 2, but for $\mathrm{H}_{2} \mathrm{O}$ (in ppmv) instead of $\mathrm{O}_{3}$. The distributions in vs1.2-1.4 (not shown) are nearly identical to those in vs1.1 and vs1.5.

Total ozone in Fig. 3 is compared with the NIWA record. In agreement with the observations all simulations show the well-known features of highest total ozone values in boreal spring, low total ozone in the tropics with a small seasonal cycle, a relative maximum in the middle latitudes in late winter/early spring and a minimum ozone column in the Southern high latitudes. While in vs1.1, the winter/ springtime maximum at middle latitudes was significantly underestimated in the northern (southern) hemisphere by 5-12\% (5$15 \%$ ), the differences are much reduced in vs 2.0 with the northern hemispheric maximum now being only $2-5 \%$ lower than in the NIWA dataset, and the southern hemispheric values even $0-5 \%$ higher than in the observations. As consequence of the underestimated springtime ozone maximum, the amplitude of the seasonal cycle in Northern Hemisphere mid-latitude total ozone was underestimated by a factor of two in vs1.1 (not shown). In this respect, the behaviour of the model improved only slightly in vs 2.0 , still showing a significantly reduced amplitude compared to NIWA (45\%). The reduced amplitude of the seasonal cycle in ozone is found in all model layers of the lower stratosphere and is connected to remaining mass fixing problems (Sect. 4.4): A simulation with the mass fixer completely switched off for ozone showed that the model is able to simulate a seasonal ozone cycle even more pronounced than observed (not shown). Overall, simu- lation vs2.0 is closest to observations, and due to restricting the ozone mass fixer to $40^{\circ} \mathrm{S}-40^{\circ} \mathrm{N}$, it shows a significantly better agreement with NIWA data in the middle and high latitudes of the Northern hemisphere than vs1.1.

Simulated and observed water vapour is shown in Fig. 9. SOCOL captures the general shape of the observed stratospheric $\mathrm{H}_{2} \mathrm{O}$ distribution: mixing ratios increase with height and with latitude, and are minimal in the polar vortex and near the tropical cold point with lowest values in March (Fig. 9b). Compared to vs1.1, where stratospheric water vapour was generally overestimated by $30-40 \%$ compared to HALOE throughout the stratosphere, the overall agreement with observations is much better for vs2.0. With exception of the lower tropical stratosphere, simulated water vapour now has only a slight negative bias $(2-12 \%)$ compared to HALOE, mainly as a result of a too cold tropical tropopause $(\sim 3 \mathrm{~K})$ in SOCOL. At $50 \mathrm{hPa}$, tropical water vapour is underestimated by more than $30 \%$ compared to observations in vs2.0 during January-May (Fig. 9d), but lies close to observations during August-November (Fig. 9e). This is related to a too fast upward transport of the tape recorder signal in the model combined with a too weak attenuation of the amplitude of the signal (c.f. Eyring et al., 2006, their Fig. 9). Consequently, as shown in Fig. 10, the seasonal cycle of simulated tropical water vapour is well captured at the tropical 
(a) $\mathrm{H}_{2} \mathrm{O} 100 \mathrm{hPa}$ Equator

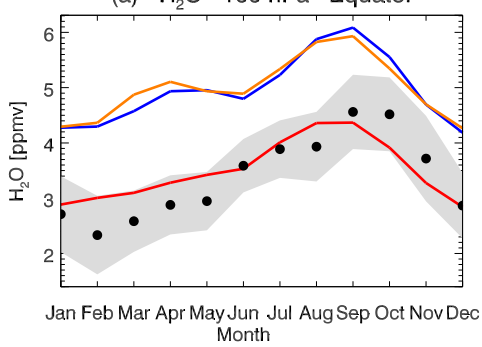

(b) $\mathrm{H}_{2} \mathrm{O} 50 \mathrm{hPa}$ Equator

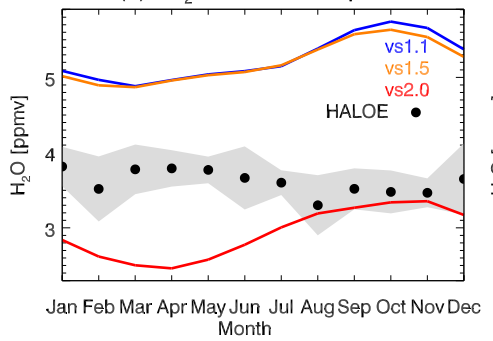

(c) $\mathrm{H}_{2} \mathrm{O} 30 \mathrm{hPa}$ Equator

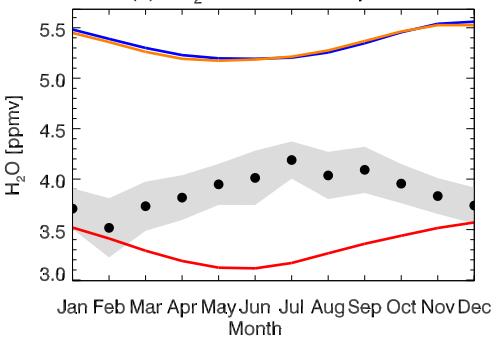

Fig. 10. Seasonal variations of $\mathrm{H}_{2} \mathrm{O}$ mixing ratios (in ppmv) at Equator averaged over 1990-1999. (a) at $100 \mathrm{hPa}$, (b) at 50 hPa, and (c) at $30 \mathrm{hPa}$. The different colours indicate the different model versions as indicated in the centre panel. Black bullets: HALOE observations; grey area: HALOE \pm 1 standard deviation $(\sigma)$ about the climatological zonal mean.
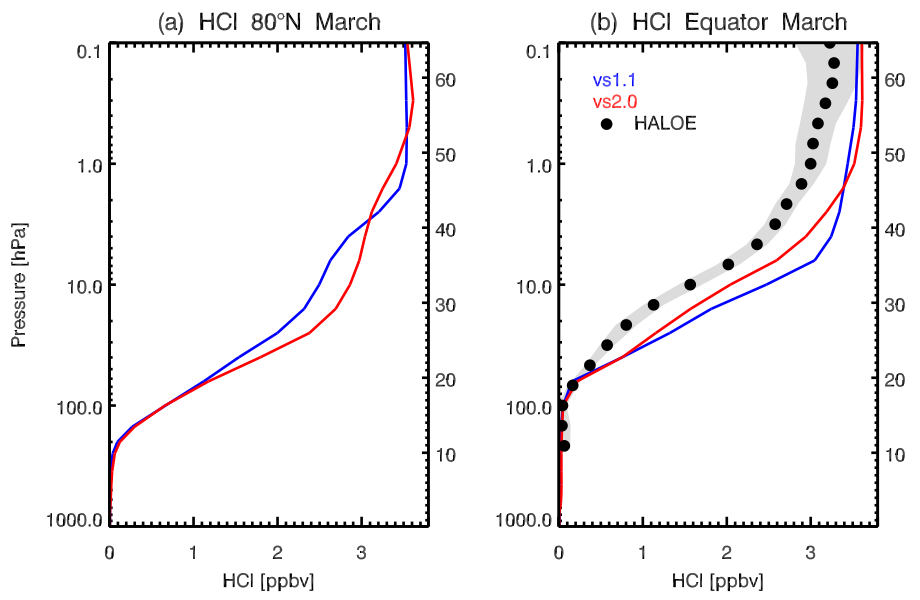

(d) $\mathrm{HCl} 50 \mathrm{hPa}$ March

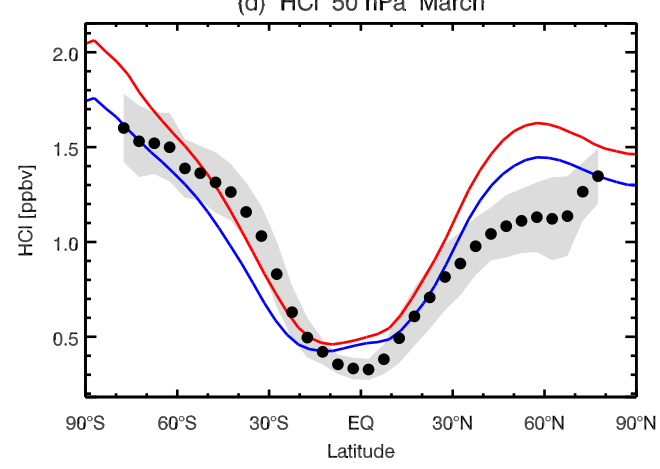

(c) $\mathrm{HCl} 80^{\circ} \mathrm{S}$ October

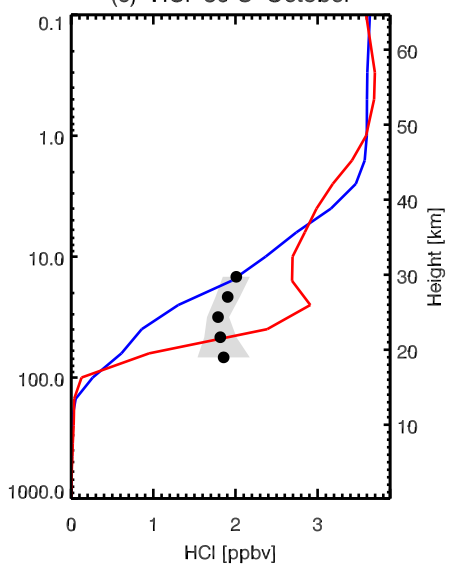

(e) $\mathrm{HCl} 50 \mathrm{hPa}$ October

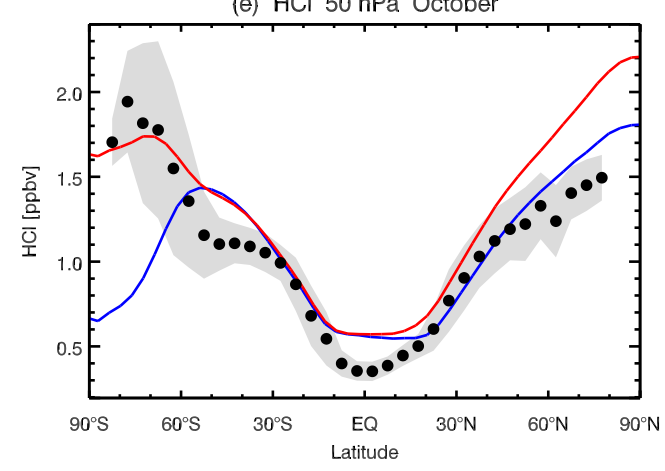

Fig. 11. Same as in Fig. 2, but for $\mathrm{HCl}$ in ppbv.

tropopause at $100 \mathrm{hPa}$, but lies out of phase by 4 months $(5.5$ months) compared to observations at $50 \mathrm{hPa}(30 \mathrm{hPa})$.

Methane is increased in the whole stratosphere by $5-15 \%$ in vs2.0 compared to vs1.1 (not shown) because of reduced $\mathrm{HO}_{\mathrm{x}}$. The decrease of $\mathrm{HO}_{\mathrm{x}}$ is caused by the new treatment of water vapour (decreased stratospheric $\mathrm{H}_{2} \mathrm{O}$ ), and by familybased mass fixing of nitrogen oxides (enhanced formation of $\mathrm{HNO}_{3}$ ). In the lower and middle stratosphere, simulated $\mathrm{CH}_{4}$ in vs2.0 is only slightly higher (0-10\%) than HALOE measurements (not shown). However, in the upper stratosphere and in the mesosphere, modelled methane is significantly overestimated in comparison with HALOE (20-50\%), which might be related to underestimated methane destruction by the hydroxyl radical or methane photolysis in the Lyman- $\alpha$ line (not shown).

Furthermore, we compared modelled $\mathrm{HCl}$ with $\mathrm{HALOE}$ $\mathrm{HCl}$ satellite retrievals (Fig. 11). $\mathrm{HCl}$ is the most important reservoir species for the chlorine group, and its mixing ratio characterises the total reactive chlorine available for ozone chemistry. The observed increase in $\mathrm{HCl}$ with altitude is 
well captured by SOCOL (Fig. 11b). In the middle and upper stratosphere, $\mathrm{HCl}$ is nearly independent of latitude both in observations and in simulations (not shown). In the high Southern latitudes of the lower stratosphere, where $\mathrm{HCl}$ was underestimated by $40-80 \%$ in vs 1.1 , the model bias for vs 2.0 is significantly reduced (Fig. 11e). In the tropical lower stratosphere, simulated $\mathrm{HCl}$ is approximately $40 \%(50 \%)$ higher than observed in March (October) in vs2.0 (Fig. 11d, e), which might be connected to remaining mass fixer problems of $\mathrm{Cl}_{\mathrm{y}}$ during the presence of the Southern polar vortex. This overestimation of $\mathrm{HCl}$ is partly transported upward into the upper stratosphere, see Fig. 11b.

Finally, Fig. 12 presents total inorganic chlorine $\left(\mathrm{Cl}_{\mathrm{y}}\right)$ at Southern high latitudes of the lower stratosphere during 1975-2000 for the month of October. Also shown are estimates for $\mathrm{Cl}_{\mathrm{y}}$ based on $\mathrm{HCl}$ HALOE measurements (Douglass et al., 1995; Santee et al., 1996) and $\mathrm{Cl}_{\mathrm{y}}$ simulated by the other models participating in the recent CCMVal intercomparison (adapted from Fig. 12b, Eyring et al., 2006). Compared to vs1.1, which participated in the CCMVal intercomparison, $\mathrm{Cl}_{\mathrm{y}}$ in vs 2.0 is considerably improved and is now in better agreement with other CCMs. However, similarly as the two other models using semi-Lagrangian schemes (E39/C, MRI), $\mathrm{Cl}_{\mathrm{y}}$ in vs2.0 still lies in the lower range of the participating CCMs. On the one hand this might be related to the minimum in total organic and inorganic chlorine $\left(\mathrm{CCl}_{\mathrm{y}}\right)$ at high latitudes in late winter/early spring due to remaining mass fixer problems (Fig. 4b). On the other hand, Struthers et al. $(2008)^{2}$ showed that the mean age of air in SOCOLvs2.0 is between 1 and 2.5 years younger than that derived from measurements. Thus, ozone depleting substances in the model have less time to break down than in real atmosphere leading to an underestimation of simulated $\mathrm{Cl}_{\mathrm{y}}$.

\section{Summary}

This paper presented a description of version 2.0 of the CCM SOCOL. In this new model version, most of the shortcomings of version 1.1 described in Eyring et al. (2006) have been eliminated or considerably reduced.

We showed that several model deficiencies of vs1.1 result from applying an insufficient description of the transport of the chemical species. For instance, unusually high total inorganic $\mathrm{Cl}_{\mathrm{y}}$ concentrations in the middle and upper stratosphere in vs1.1 are caused by an artificial accumulation of $\mathrm{ClO}$ not transported in vs1.1. In vs2.0 the number of transported species was increased by 19 to allow all 41 substances of SOCOL to be transported individually. The much too

\footnotetext{
${ }^{2}$ Struthers, H., Bodeker, E., Smale, D., Rozanov, E., Schraner, M., and Peter, T.: The interaction between photochemistry and transport in determining stratospheric inorganic chlorine in two coupled chemistry-climate models, Geophys. Res. Lett., in review, 2008.
}

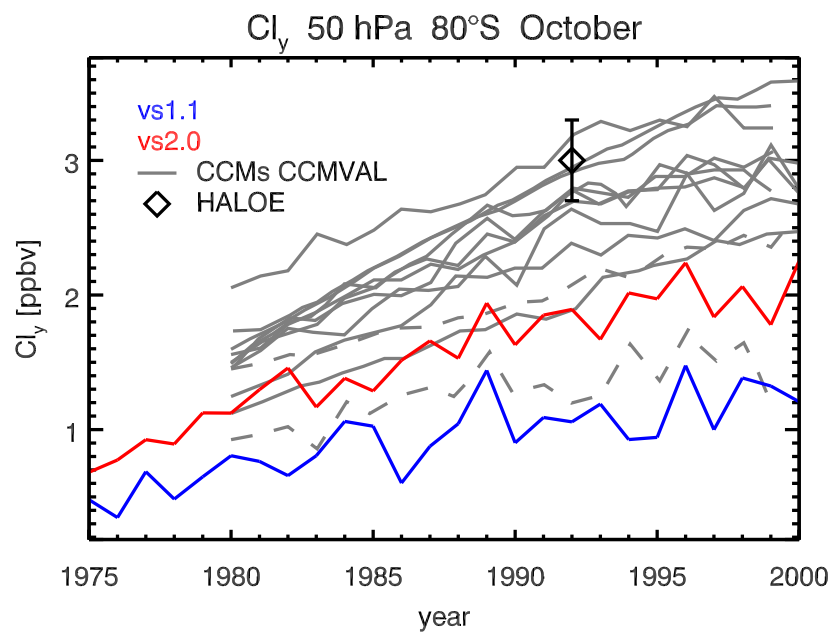

Fig. 12. Time series of total inorganic chlorine $\mathrm{Cl}_{\mathrm{y}}$ in October at $50 \mathrm{hPa}$ and $80^{\circ} \mathrm{S}$ for SOCOL versions vs1.1 (blue line) and vs2.0 (red line). The grey lines indicate values simulated by the CCMs participating at the CCMVal intercomparison except SOCOL. Values of the two other models using semi-Lagrangian schemes (E39/C, MRI) are dashed. Estimates of $\mathrm{Cl}_{\mathrm{y}}$ from HALOE $\mathrm{HCl}$ measurements in 1992 are also shown. Adapted from Fig. 12b from Eyring et al (2006).

low $\mathrm{Cl}_{\mathrm{y}}$ concentrations at high latitudes of the lower stratosphere in winter/early spring in vs1.1 are directly related to the semi-Lagrangian scheme used in the model for horizontal transport. Since this scheme is not mass conserving, a mass fixer according to Williamson and Rasch (1995) is applied after every transport step, which ensures mass conservation of the transported species within each horizontal model layer. However, applying the mass fixer of Williamson and Rasch to each transported species can lead to artificial mass accumulation or mass loss of the respective families $\left(\mathrm{NO}_{\mathrm{y}}\right.$, $\mathrm{Cl}_{\mathrm{y}}$, and $\mathrm{Br}_{\mathrm{y}}$ ) in particular geographical regions, most significantly in the region of the polar vortex. In vs2.0, $\mathrm{NO}_{\mathrm{y}}$, $\mathrm{Cl}_{\mathrm{y}}$, and $\mathrm{Br}_{\mathrm{y}}$ are transported in addition to the individual family members and their mixing ratios are used to correct the mixing ratios of the members. The method of familybased mass fixing combined with individually transporting all species leads to significant improvement of the nitrogen, chlorine and bromine containing species. Especially in the region of the Southern polar vortex, modelled $\mathrm{Cl}_{\mathrm{y}}$ and $\mathrm{HCl}$ are much closer to observations in vs2.0 than in vs1.1.

For ozone, the concept of family-based fixing cannot be applied, as no corresponding family exists. For this reason, to provide an alternative solution, we restrict mass fixing of ozone to $40^{\circ} \mathrm{S}-40^{\circ} \mathrm{N}$ in vs 2.0 to take into account that the mass fixer of Williamson and Rasch leads to unjustified corrections of ozone at high latitudes, although about half of the transport error is produced in the tropics and subtropics. Both the modified mass fixer for ozone and the changed catalytic ozone cycles due to modified distributions of $\mathrm{HO}_{\mathrm{x}}$, $\mathrm{NO}_{\mathrm{x}}, \mathrm{ClO}_{\mathrm{x}}$, and $\mathrm{Br}_{\mathrm{y}}$ have a significant influence on simulated 
ozone. Compared to vs1.1, modelled ozone in vs2.0 is improved especially in the region of the Southern polar vortex, where the simulated vertical ozone profile is much closer to observations.

Stratospheric water vapour, which is overestimated by 30 $40 \%$ in vs1.1, is significantly improved in vs 2.0 now taking into account that clouds in the tropics and subtropics can also be formed above $100 \mathrm{hPa}$. Compared to satellite observations, simulated $\mathrm{H}_{2} \mathrm{O}$ of vs 2.0 is slightly underestimated mainly because of a cold temperature bias $(\sim 3 \mathrm{~K})$ at the tropical tropopause.

The new model version also includes a more comprehensive halogen chemistry treating all chemical reactions of the ODS species individually. However, the influence on chlorine and bromine containing species and on catalytic ozone destruction is relatively low.

Overall, SOCOL vs 2.0 shows a significantly improved performance with respect to a more realistic simulation of stratospheric chemical species, most notably for chlorine and water vapour. Hence, the new model version is an appropriate tool for studying a variety of chemistry-climate problems of the middle atmosphere. Due to its good wall-clock performance and the possibility to run the model on regular PCs (one model year requires about two CPU days on stateof-the-art PCs), its main advantage lies in the feasibility to carry out long-term transient ensemble simulations independent from the availability of a supercomputer (e.g., Fischer et al., 2008). We continue to offer the model for use by other research groups without access to large supercomputer facilities.

Acknowledgements. The development and maintenance of SOCOL CCM is part of the project "Variability of the Sun and Global Climate" and funded by ETH Zurich grant PP-1/04-1. VZ was partially supported by the Swiss National Science Foundation (grant SCOPES IB7320-110884). We thank NASA for providing the HALOE satellite retrievals, and the NIWA Data Center for the total ozone data set. The Neumayer ozone sonde data were obtained from the World Ozone and Ultraviolet Radiation Data Centre (WOUDC) operated by Environment Canada, Toronto, Ontario, Canada under the auspices of the World Meteorological Organization.

Edited by: M. Dameris

\section{References}

Austin, J., Shindell, D., Beagley, S. R., Brühl, C., Dameris, M., Manzini, E., Nagashima, T., Newman, P., Pawson, S., Pitari, G., Rozanov, E., Schnadt, C., and Shepherd, T. G.: Uncertainties and assessments of chemistry-climate models of the stratosphere, Atmos. Chem. Phys., 3, 1-27, 2003, http://www.atmos-chem-phys.net/3/1/2003/.

Bodeker, G. E., Shiona, H., and Eskes, H.: Indicators of Antarctic ozone depletion, Atmos. Chem. Phys., 5, 2603-2615, 2005, http://www.atmos-chem-phys.net/5/2603/2005/.
Carslaw, K. S., Luo, B. P., and Peter T.: An analytic-expression for the composition of aqueous $\mathrm{HNO}_{3}-\mathrm{H}_{2} \mathrm{SO}_{4}$ stratospheric aerosols including gas-phase removal of $\mathrm{HNO}_{3}$, Geophys. Res. Lett., 22(14), 1877-1880, 1995.

Courant, R., Friedrichs, K., and Levy, H.: Über die partiellen Differenzengleichungen der mathematischen Physik, Math. Annalen, 100, 32-74, 1928.

Dameris, M., Greve, V., Ponater, M., Deckert, R., Eyring, V., Mager, F., Matthes, S., Schnadt, C., Stenke, A., Steil, B., Brühl, C., and Giorgetta, M. A.: Long-term changes and variability in a transient simulation with a chemistry-climate model employing realistic forcing, Atmos. Chem. Phys., 5, 2121-2145, 2005, http://www.atmos-chem-phys.net/5/2121/2005/.

Douglass, A. R., Schoeberl, M. R., Stolarski, R. S., Waters, J. W., Russell II, J. M., and Roche, A. E.: Interhemispheric differences in springtime production of $\mathrm{HCl}$ and $\mathrm{ClONO}_{2}$ in the polar vortices, J. Geophys. Res., 100, 13 967-13 978, 1995.

Egorova, T., Rozanov, E., Schlesinger, M. E., Andronova, N. G., Malyshev, S. L., Zubov, V., and Karol, I. L.: Assessment of the effect of the Montreal Protocol on atmospheric ozone, Geophys. Res. Lett., 28, 2389-2392, 2001.

Egorova, T., E. Rozanov, V. Zubov, and I. L. Karol: Model for Investigating Ozone Trends (MEZON), Izvestiya, Atmospheric and Oceanic Physics, 39, 277-292, 2003.

Egorova, T., Rozanov, E., Manzini, E., Haberreiter, M., Schmutz, W., Zubov, V., and Peter, T.: Chemical and Dynamical Response to the 11-year Variability of the Solar Irradiance Simulated with a Chemistry-Climate Model, Geophys. Res. Lett., 83, 6225-6230, 2004.

Egorova, T., Rozanov, E., Zubov, V., Manzini, E., Schmutz, W., and Peter, T.: Chemistry-climate model SOCOL: a validation of the present-day climatology, Atmos. Chem. Phys., 5, 1557-1576, 2005 , http://www.atmos-chem-phys.net/5/1557/2005/.

Eyring, V., Butchart, N., Waugh, D. W., Akiyoshi, H., Austin, J., Bekki, S., Bodeker, G. E., Boville, B. A., Brühl, C., Chipperfield, M. P., Cordero, E., Dameris, M., Deushi, M., Fioletov, V. E., Frith, S. M., Garcia, R. R., Gettelman, A., Giorgetta, M. A., Greve, V., Jourdain, L., Kinnison, D. E., Mancini, E., Manzini, E., Marchand, M., Marsh, D. R., Nagashima, T., Newman, P. A., Nielsen, J. E., Pawson, S., Pitari, G., Plummer, D. A., Rozanov, E., Schraner, M., Shepherd, T. G., Shibata, K., Stolarski, R. S., Struthers, H., Tian, W., and Yoshiki, M.: Assessment of temperature, trace species, and ozone in chemistry-climate model simulations of the recent past, J. Geophys. Res., 111, D22308, doi:10.1029/2006JD007327, 2006.

Fouqart, Y., and B. Bonnel, Computations of solar heating of the Earth's atmosphere: A new parameterization, Beitr. Phys. Atmos., 53, 35-62, 1980.

Fischer, A. M., Schraner, M., Rozanov, E., Kenzelmann, P., Schnadt Poberaj, C., Brunner, D., Lustenberger, A., Luo, B. P., Bodeker, G. E., Egorova, T., Schmutz, W., Peter, T., and Brönnimann, S.: Interannual-to-decadal variability of the stratosphere during the 20th century: ensemble simulations with a chemistry-climate model, Atmos. Chem. Phys. Discuss., 8, 14371-14 418, 2008, http://www.atmos-chem-phys-discuss.net/8/14371/2008/.

Giorgetta, M. A.: Der Einfluss der quasi-zweijährigen Oszillation: Modellrechnungen mit ECHAM4, Max-Planck-Institut für Meteorologie, Hamburg, Examensarbeit Nr. 40, MPI-Report 218, 
1996.

Haberreiter, M., Krivova, N. A., Schmutz, W., and Wenzler, T.:, Restruction of the solar UV irradiance back to 1974, Adv. Space Res., 59, 365-369, 2005.

Hanson, D., and Ravishankara, A.: Reactive Uptake of $\mathrm{ClONO}_{2}$ onto Sulfuric Acid Due to Reaction with $\mathrm{HCl}$ and $\mathrm{H}_{2} \mathrm{O}$, J. Phys. Chem., 98, 5728-5735, 1994.

Hanson, D., Ravishankara, A., and Lovejoy, E. R.:, Reaction of $\mathrm{BrONO}_{2}$ with $\mathrm{H}_{2} \mathrm{O}$ on submicron sulfuric acid aerosol and the implications for the lower stratosphere, J. Geophys. Res., 101(D4), 9063-9069, 1996.

Hauglustaine, D. A., Granier, C., Brasseur, G., and Megie G.: The importance of atmospheric chemistry in the calculation of radiative forcing on the climate system, J. Geophys. Res., 99, 11731186, 1994.

Hines, C. O.: Doppler spread parameterization of gravity wave momentum deposition in the middle atmosphere, 1, Basic formulation, J. Atmos. Solar Terr. Phys., 59, 371-386, 1997a.

Hines, C. O.: Doppler spread parameterization of gravity wave momentum deposition in the middle atmosphere, 2, Broad and quasi monochromatic spectra and implementation, J. Atmos. Solar Terr. Phys., 59, 387-400, 1997b.

Horowitz, L. W., Walters, S., Mauzerall, D. L., Emmons, L. K., Rasch, P. J., Granier, C., Tie, X., Lamarque, J.-F., Schultz, M. G., Tyndall, G. S., Orlando, J. J., and Brasseur, G. P.: A global simulation of tropospheric ozone and related tracers: Description and evaluation of MOZART, version 2, J. Geophys. Res., 108(D24), 4784, doi:10.1029/2002JD002,853, 2003.

Hoyle, C. R.: Three dimensional chemical transport model study of ozone and related gases 1960-2000, Eidgenössische Technische Hochschule, Zürich, Dissertation No. 16271, 2005.

Intergovernmental Panel on Climate Change (IPCC): Special report on aviation and the global atmosphere, edited by: Penner, J. E., Lister, D. H., Griggs, D. J., Dokken, D. J., McFarland, M., Cambridge University Press, Cambridge, UK and New York, NY, USA, 373 pp., 1999.

Intergovernmental Panel on Climate Change (IPCC): The scientific basis, Contribution of working group I to the third assessment report of the Intergovernmental Panel on Climate Change, Cambridge University Press, Cambridge, UK and New York, NY, USA, 2001.

Intergovernmental Panel on Climate Change (IPCC): The Physical Science Basis, Working group I contribution to the fourth assessment report of the IPCC, Intergovernmental Panel on Climate Change, Cambridge University Press, Cambridge, UK and New York, NY, USA, 2007.

Labitzke, K.: On interannual variability of the middle stratosphere during northern winters, J. Meteorol. Soc. Jpn., 60, 124-139, 1982.

Lean, J.: Evolution of the sun's spectral irradiance since the maunder minimum, Geophys. Res. Lett., 27(16), 2425-2428, 2000.

Lohmann, U., Feichter, J., Chuang, C. C., and Penner, J.: Prediction of the number of cloud droplets in the ECHAM GCM, J. Geophys. Res., 104(D8), 9169-9198, 1999.

Manzini, E. and L. Bengtsson: Stratospheric climate and variability from a general circulation model and observations, Clim. Dyn., 12, 615-639, 1996.
Manzini, E., McFarlane, N. A., and McLandress, C.: Impact of the Doppler Spread Parameterization on the simulation of the middle atmosphere circulation using the MA/ECHAM4 general circulation model, J. Geophys. Res., 102, 25 751-25 762, 1997.

Manzini, E. and Feichter, J.: Simulation of the $\mathrm{SF}_{6}$ tracer with the middle atmosphere MAECHAM4 model: Aspects of the largescale transport, J. Geophys. Res., 104, 31 097-31 108, 1999.

Morcrette, J. J.: Radiation and cloud radiative properties in the European Center for Medium-Range Weather Forecasts forecasting system, J. Geophys. Res., 96, 9121-9132, 1991.

Müller, J.-F. and Brasseur, G.:, IMAGES: A three-dimensional chemical transport model of the global troposphere, J. Geophys. Res., 100, 16445-16 490, 1995.

Murphy, D. M. and Koop, T.: Review of the vapour pressures of ice and supercooled water for atmospheric applications, Q. J. R. Meteorol. Soc., 131(608), 1539-1565, 2005.

Ozolin, Y.: Modelling of diurnal variations of gas species in the atmosphere and diurnal averaging in photochemical models, Izv. Akad. Nauk. Phys. Atmos. Ocean., 28(12), 135-143, 1992.

Prather, M. J.: Numerical Advection by Conservation of SecondOrder Moments, J. Geophys. Res., 91, 6671-6681, 1986.

Pruppacher, H. and Klett, J.: Microphysics of clouds and precipitation, Springer, Dordrecht, The Netherlands, 2nd edition, 1997.

Rayner, N. A., Parker, D. E., Horton, E. B., Folland, C. K., Alexander, L. V., and Rowell, D. R.: Global analyses of sea surface temperature, sea ice, and night marine air temperature since the late nineteenth century, J. Geophys. Res., 108(D14), doi:10.1029/2002JD002,670, 2003.

Ritchie, H.: Application of a semi-Lagrangian integration scheme to the moisture equation in a regional forecast model, Mon. Weather Rev., 113, 424-435, 1985.

Roeckner, E., Arpe, K., Bengtsson, L., Christoph, M., Claussen, M., Dümenil, L., Esch, M., Giorgetta, M., Schlese, U., and Schulzweida, U.: The atmospheric general circulation model ECHAM4: Model description and simulation of the present-day climate, Max-Planck-Institut für Meteorologie, Hamburg, Report No. 218, 1996.

Rozanov, E., Schlesinger, M. E., Zubov, V., Yang, F., and Andronova, N. G.: The UIUC three-dimensional stratospheric chemical transport model: Description and evaluation of the simulated source gases and ozone, J. Geophys. Res., 104, 11755$11781,1999$.

Rozanov, E., Schlesinger, M. E., and Zubov, V.: The University of Illinois, Urbana-Champaign three-dimensional stratospheretroposphere general circulation model with interactive ozone photochemistry: Fifteen-year control run climatology, J. Geophys. Res., 106, 27 233-27 254, 2001.

Rozanov, E., Schraner, M., Schnadt, C., Egorova, T., Wild, M., Ohmura, A., Zubov, V., Schmutz, W., and Peter, T.: Assessment of the ozone and temperature variability during 1979-1993 with the chemistry climate model SOCOL, Adv. Space. Res., 35(8), 1375-1384, 2005.

Sander, S. P., Friedl, R. R., DeMore, W. B., Golden, D. M., Kurylo, M. J., Hampson, R. F., Huie, R. E., Moortgat, G. K., Ravishankara, A. R., Kolb, C. E., and Molina, M. J.: Chemical kinetics and photochemical data for use in stratospheric data, supplemented to evaluation 12: Update of key reactions, JPL Publication $00-3,2000$. 
Santee, M. L., Froidevaux, L., Manney, G. L., Read, W. G., Waters, J. W., Chipperfield, M. P., Roche, A. E., Kumer, J. B., Mergenthaler, J. L., and Russel, J. M.: Chlorine deactivation in the lower stratospheric polar regions during late winter: Results from UARS, J. Geophys. Res., 101, 18 835-18 860, 1996.

Schmitt, A. and Brunner, B.: Emissions for aviation and their development over time, Pollutants form air-traffic - results of atmospheric research 1992-1997, DLR-Mitt. 97-04, edited by: Schumann, U., Chlond, A., Ebel, A., Kärcher, B., Pate, H., Schlager, H., Schmitt, A., and Wendling, P., DLR Köln, Germany, 37-52, 1997.

Schultz, M. G., Heil, A., Hoelzemann, J. J., Spessa, A., Thonicke, K., Goldammer, J., Held, A. C., and Pereira, J. M.: Global Emissions from Wildland Fires from 1960 to 2000, Global Biogeochem. Cy., 22, GB2002, doi:10.1029/2007GB003031, 2008a.

Sinnhuber, B.-M., Rozanov, A., Sheode, N., Afe, O. T., Richter, A., Sinnhuber, M., Wittrock, F., Burrows, J. P., Stiller, G. P., von Clarmann, T., and Linden, A.: Global observations of stratospheric bromine monoxide form SCIAMACHY, Geophys. Res. Lett., 32, L20810, doi:10.1029/2005GL023839, 2005.

Stott, P. A. and Harwood, R. S.: An implicit time-stepping scheme for chemical species in a global atmospheric circulation model, Ann. Geophys., 11, 377-388, 1993, http://www.ann-geophys.net/11/377/1993/.
Strobel, D. F.: Parameterization of the atmospheric heating rate from 15 to $120 \mathrm{~km}$ due to $\mathrm{O}_{2}$ and $\mathrm{O}_{3}$ absorption of solar radiation, J. Geophys. Res., 83, 6225-6230, 1978.

Thomason, L. and Peter, T.: Assessment of Stratospheric Aerosol Properties (ASAP), SPARC Report No. 4., WCRP-124, WMO/TD-No. 1295, 2006.

Turman, B. N. and Edgar, B. C.: Global lightning distributions at drawn and dusk, J. Geophys. Res., 87, 1191-1206, 1982.

Williamson, D. L. and Rasch, P. J.: Two-dimensional semiLagrangian transport with shape-preserving interpolation, Mon. Weather Rev., 117, 102-129, 1989.

WMO, World Meteorological Organization: Meteorology - a threedimensional science, 230 WMO Bull., 6, 134-138, 1957.

WMO: Scientific assessment of ozone depletion: 2002, Global ozone research and monitoring project-report No. 47, World Meteorological Organization, Geneva, Switzerland, 2003.

WMO: Scientific assessment of ozone depletion: 2006, Global ozone research and monitoring project-report No. 50, World Meteorological Organization, Geneva, Switzerland, 2006.

Zubov, V., Rozanov, E., and Schlesinger, M. E.: Hybrid scheme for three-dimensional advective transport, Mon. Weather Rev., 127(6), 1335-1346, 1999. 